\title{
Article \\ JI017, a Complex Herbal Medication, Induces Apoptosis via the Nox4-PERK-CHOP Axis in Ovarian Cancer Cells
}

\author{
Taewoo Kim (D) and Seong-Gyu Ko *(D)
}

check for

updates

Citation: Kim, T.; Ko, S.-G. JI017, a Complex Herbal Medication, Induces Apoptosis via the

Nox4-PERK-CHOP Axis in Ovarian Cancer Cells. Int. J. Mol. Sci. 2021, 22, 12264. https://doi.org/10.3390/ ijms222212264

Academic Editors: Nalini Santanam and Maurizio Battino

Received: 26 July 2021

Accepted: 11 November 2021

Published: 12 November 2021

Publisher's Note: MDPI stays neutral with regard to jurisdictional claims in published maps and institutional affiliations.

Copyright: (c) 2021 by the authors. Licensee MDPI, Basel, Switzerland. This article is an open access article distributed under the terms and conditions of the Creative Commons Attribution (CC BY) license (https:/ / creativecommons.org/licenses/by/ $4.0 /)$.
Department of Preventive Medicine, College of Korean Medicine, Kyung Hee University, Seoul 130-701, Korea; tae1410@naver.com

* Correspondence: epiko@khu.ac.kr; Tel.: +82-2-961-0329; Fax: +82-2-961-1165

Abstract: Many anti-cancer drugs, including paclitaxel and etoposide, have originated and been developed from natural products, and traditional herbal medicines have fewer adverse effects and lesser toxicity than anti-tumor reagents. Therefore, we developed a novel complex herbal medicine, JI017, which mediates endoplasmic reticulum (ER) stress and apoptosis through the Nox4PERK-CHOP signaling pathway in ovarian cancer cells. JI017 treatment increases the expression of GRP78, ATF4, and CHOP and the phosphorylation of PERK and eIF2 $\alpha$ via the upregulation of Nox4. Furthermore, it increases the release of intracellular reactive oxygen species (ROS), the production of intracellular $\mathrm{Ca}^{2+}$, and the activation of exosomal GRP78 and cell lysate GRP78. Combination treatment using the sarco/endoplasmic reticulum $\mathrm{Ca}^{2+}$-ATPase inhibitor thapsigargin (TG) and JI017 reportedly induces increased ER stress and cell death in comparison to the control; however, knockdown experiments of PERK and CHOP indicated suppressed apoptosis and ER stress in JI017-treated ovarian cancer cells. Furthermore, targeting Nox4 using specific siRNA and pharmacological ROS inhibitors, including $\mathrm{N}$-acetylcystein and diphenylene iodonium, blocked apoptosis and ER stress in JI017-treated ovarian cancer cells. In the radioresistant ovarian cancer model, when compared to JI017 alone, JI017 co-treatment with radiation induced greater cell death and resulted in overcoming radioresistance by inhibiting epithelial-mesenchymal-transition-related phenomena such as the reduction of E-cadherin and the increase of N-cadherin, vimentin, Slug, and Snail. These findings suggest that JI017 is a powerful anti-cancer drug for ovarian cancer treatment and that its combination treatment with radiation may be a novel therapeutic strategy for radioresistant ovarian cancer.

Keywords: JI017; ER stress; ROS; Nox4; exosome

\section{Introduction}

Ovarian cancer is the fifth most common cancer occurring in woman globally [1]. Ovarian tumors can derive from three cell types: epithelial cells, germ cells, and stromal cells [2]. Approximately $90 \%$ of ovarian tumors originate from epithelial cells, however, $2-3 \%$ from germ cells and $5-6 \%$ from stromal cells [3]. Chemotherapy is a very strong therapeutic strategy for patients with ovarian cancer [4]. Despite the development of ovarian cancer therapies, such as surgery, chemotherapy, hormone therapy, targeted therapy, immune therapy, and radiation therapy, the cancer is often chemoresistant [5]. Many studies reported that the epithelial-mesenchymal transition (EMT) causes chemoresistance on cancer therapy using anti-cancer reagents such as paclitaxel and carboplatin [6]. EMT is a driver for chemoresistance via various mechanisms such as MAPK/ERK, TGF $\beta$-SMAD, JAK/STAT, PI3K-AKT [7]. The molecular mechanisms leading to therapy resistance by the EMT process are still not clear and require deeper insight. To overcome this chemoresistance, we need to suggest a new treatment strategy for recurrent ovarian cancer so that patients receive the most effective therapy. Herbal medicines extracted from plants may be potential anti-cancer therapeutics to overcome chemoresistance [8]. 
We developed and studied a novel complex herbal medication JI017 with intensive anti-tumor effects in various cancer types. JI017 is a combination of herbal extracts from Angelica gigas (Ag), Zingiber officinale Roscoe (Zo), and Aconitum carmichaeli (Ac) in the ratio of 2:1:1. The anti-cancer effects of $\mathrm{Ag}, \mathrm{Zo}$, and Ac individually have been well reported in many cancer cells, including pancreatic cancer, liver cancer, breast cancer, lung cancer, and oral cancer [9-12]. Ag ethanol extracts induce caspase-3-dependent apoptosis by inhibiting MMP-2 and MMP-9 in Human pancreatic cancer cells [9]. Zo ethanol extracts mediate caspase-3-dependent apoptosis by activating autophagic cell death and cell cycle arrest [13]. Ac extracts exert an anti-inflammatory effect, but other effects are not clear [14].

Radiotherapy is a powerful tumor therapeutic strategy used in most cases of cancer [15]. However, radioresistance can still be acquired, and this problem is a serious obstacle to cancer therapy [16]. Molecular mechanism studies to overcome radioresistance are necessary and understanding the biological functions that vary between radiosensitivity and radioresistance may suggest novel strategies for potential anti-cancer effects by overcoming radioresistance. EMT is a biological phenomenon wherein the epithelial cells lose their properties of cell-to-cell adhesion and apicobasal polarity and become mesenchymal stem cells by gaining invasive and migratory functions [17]. In tumorigenesis and cancer progression, EMT play an important role in, and contribute to, process-acquired resistance, such as radioresistance [18]. EMT is regulated by diverse signaling pathway and markers, including loss of E-cadherin and increase of N-cadherin, vimentin, Snail, Slug, transforming growth factor- $\beta$, Wnt, EGFR, PI3K, Akt, ERK, nuclear factor-kappa B, and Notch, leading to radioresistance in various cancer types $[19,20]$. In hematopoietic progenitor cells of wild-type mice, the upregulation of the EMT marker Slug mediates chemoresistance and survival pathway after radiation exposure; however, in hematopoietic progenitor cells of Slug ${ }^{-/-}$mice, Slug knockdown induces apoptosis after radiation exposure [21]. Furthermore, downregulation of the epithelial marker E-cadherin and the upregulation of mesenchymal markers $\mathrm{N}$-cadherin and vimentin are potential factors inducing radioresistance [22].

Endoplasmic reticulum (ER) stress induces cell death via the activation of unfolded protein response (UPR) in the tumor environment, and recently, targeting ER stress to overcome chemoresistance has been shown to allow for powerful and promising anticancer strategies, such as combinatory therapies [23]. Reactive oxygen species (ROS) contribute to many diseases, and ROS-mediated stresses regulate tumor growth and are an important factor for cell death induction via the activation of ER stress [24]. Excessive ROS mediates the programmed cell death cascade, including caspase- 3 , caspase- 9 , and PARP cleavage, in various cancer types, and it may provide a powerful anti-cancer therapy strategy [25]. The NAPDH oxidase (Nox) family, including Nox2 and Nox4, regulates ROS production [26]. Furthermore, accumulating evidence indicates redox signaling regulators, including Nox4, Ero-1, and calcium, and the relationship between ROS and ER stress plays potential roles in diverse diseases, such as cancer, inflammation, and diabetes [27]. A novel transient receptor potential vanilloid 1 antagonist, DWP05195, induces cell death and ER stress by releasing ROS in ovarian cancer cells, and Nox knockdown using p47phox siRNA blocks DWP05195-mediated CHOP induction and cell death. [28]. Traditional medicine derived compounds exert anti-cancer effects via ER stress in various cancer types [29]. Polyphyllin D derived Paris polyphylla induces ER stress and cell death via GRP78, CHOP, and caspase-3 cleavage in the NSCLC cell line NCI-H460; furthermore, the Saussurea lappa and Aucklandia lappa derivative dehydrocostuslactone mediates ER stress and cell death by activating PERK-CHOP and IRE-1-JNK signaling pathways and inducing ROS and $\mathrm{Ca}^{2+}$ release in the NSCLC cell line A549 and NCI-H460 [30,31]. Guggulsterone extracted from Commiphora mukul reportedly induces apoptosis via the upregulation of GRP78, PERK, pJun N-terminal kinase (p-JNK), CHOP, and DR5 in Hep3B cells; further, CHOP knockdown inhibited the anti-cancer effect of guggulsterone [32]. 3,3'-Diindolylmethane (DIM), a bioactive compound derived from Brassica spp., including kale and broccoli, induces apoptosis via the activation of GRP78-PERK/IRE1 $\alpha-$ CHOP signaling pathway and the 
inhibition of EMT, by downregulating E-cadherin and upregulating N-cadherin, vimentin, Slug, and Snail [33]. Therefore, ER stress-apoptosis may be a potential tumor therapeutic strategy to overcome tumor progression, metastasis, invasion, and radioresistance through EMT inhibition.

Recent reports suggest that exosomes, cell-to-cell communicators, and cell-derived vesicles increase the survival ability of cancer cells during radiotherapy [34]. In contrast, exosomes released by anti-cancer drugs play a role in cell death, and therefore, therapeutic strategy using exosomes exerts potential anti-cancer effects and overcomes resistance by inhibiting EMT in the tumor environment [35]. Moreover, the activation of ER stress releases exosomes in hepatocellular carcinoma cells, and these exosomes regulate anticancer immunity through the inhibition of programmed death ligand 1 [36].

In the present study, we sought to examine whether JI017 mediates apoptosis via ER stress in ovarian cancer cells and whether JI017 regulates ER stress and cell death via the ROS pathway and the release of Nox. We identified that JI017 causes apoptosis via the PERK-ATF4-CHOP axis and $\mathrm{Ca}^{2+}$ release and induces ER stress and apoptosis by releasing Nox4 and ROS in ovarian cancer cells. Therefore, we suggest that the novel herbal medicine JI017 is a potential therapeutic for ovarian cancer.

\section{Results}

\subsection{Anti-Ovarian Cancer Effects of JI017 In Vitro and In Vivo}

To identify the anti-cancer effect of JI017 in ovarian cancer cell lines, including A2780, OVCAR-3, Caov-3, and SK-OV-3, we tested the cell viability and cytotoxicity using WST-1 and LDH assays in a dose-dependent manner (Figure 1A,B). JI017 treatment caused dosedependent reduction of cell viability and increase of $\mathrm{LDH}$ cytotoxicity in ovarian cancer cell lines when compared to the control (Figure 1A,B). To validate the effects of JI017 in vivo, an ovarian cancer xenograft mice model was constructed using A2780 cells. Mice in the 400 and $600 \mathrm{mg} / \mathrm{kg}$ JI017 groups exhibited lower tumor volumes than those in the control group (Figure 1C). The body weights of all groups were not significant (Figure 1D). To study the anti-cancer effect of JI017 in a time-dependent manner, we tested cell viability, cell cytotoxicity, and caspase- 3 activity assays using WST-1, LDH, and caspase- 3 activity assay in a time-dependent manner, respectively (Figure 1E-G). JI017 treatment induced decrease in cell viability and enhancement of LDH release and caspase-3 activity in a time-dependent manner in ovarian cancer cell lines A2780 and OVCAR-3 (Figure 1E-G). Western blot analyses in a time-dependent manner revealed that JI017 induced caspase-3, caspase-9, and PARP cleavage (Figure 1H). To confirm whether JI017 regulates caspasedependent apoptosis in ovarian cancer cells, we performed a pharmacological inhibitor experiment using the caspase inhibitor Z-VAD-FMK. Z-VAD-FMK alone did not affect cell viability, LDH cytotoxicity, and caspase-3 activity; however, JI017 alone decreased cell viability and increased LDH release and caspase-3 activity. In combination with ZVAD-FMK, JI017 dramatically inhibited the reduction of cell viability and enhancement of LDH cytotoxicity and caspase-3 activity (Figure 1I-K). Furthermore, Western blot analyses indicated that JI017 + Z-VAD-FMK blocked caspase-3 cleavage to a greater extent than JI017 alone (Figure 1L). Our finding suggested that JI017 treatment induces apoptosis in ovarian cancer cell lines. 


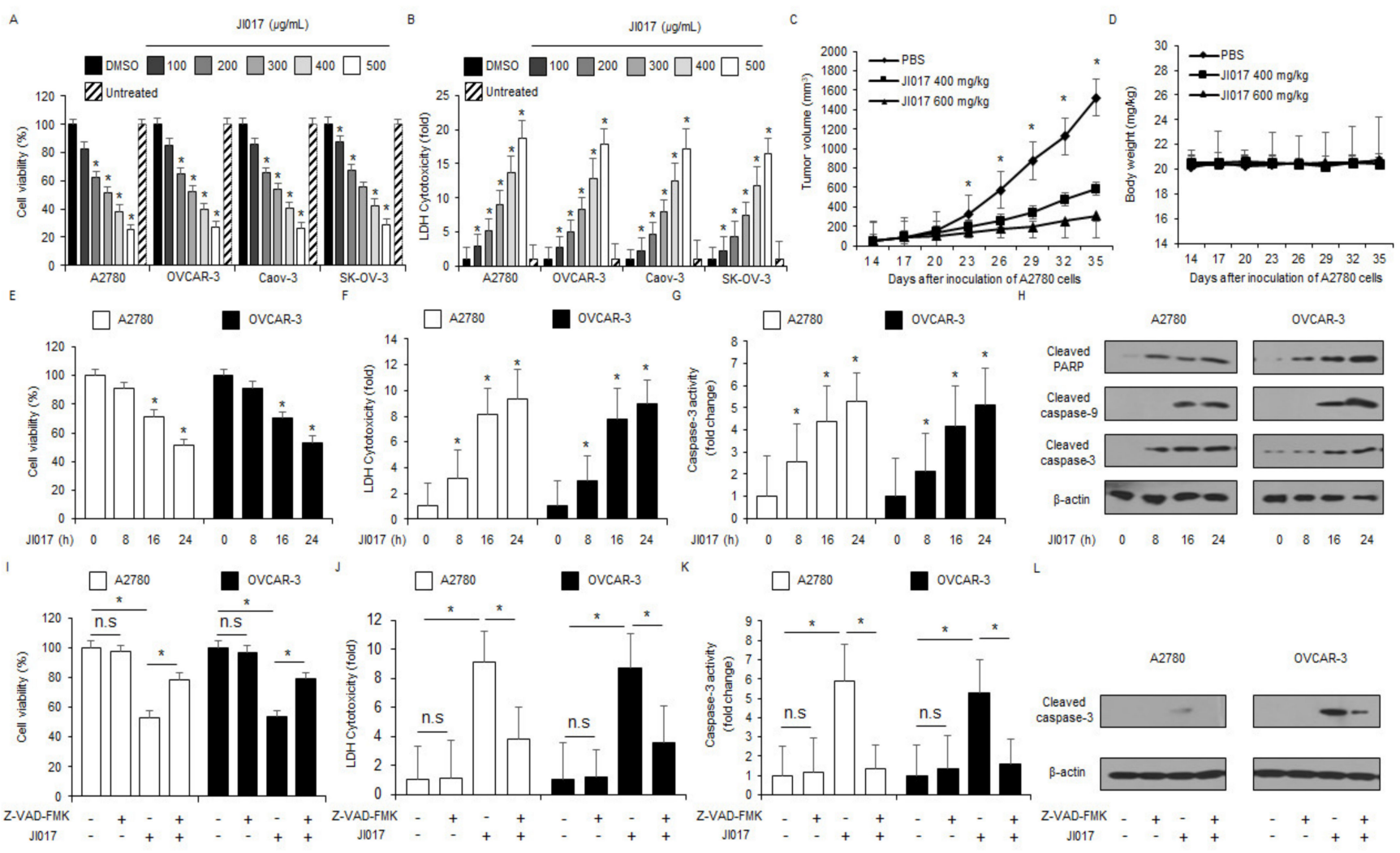

Figure 1. Cytotoxic effects of JI017 in ovarian cancer cell lines. (A,B) JI017 dose-dependent cell viability and LDH cytotoxicity in ovarian cancer cell lines, including A2780, OVCAR-3, Caov-3, and SK-OV-3, measured using the WST-1 assay and LDH assay on 96-well plates. (C,D) A2780 cells $\left(1 \times 10^{7}\right)$ were implanted (sc) into the thigh on the right hind leg of nude mice ( $\mathrm{n}=10$ /group). JI017 (400 or $600 \mathrm{mg} / \mathrm{kg}$ ) or 10\% DMSO was administered (ip) once a day for two days. The longest $(L)$ and shortest $(W)$ axes of the tumors were measured, and the tumor volume $\left(\mathrm{mm}^{3}\right)$ was calculated as LW2/2. Body weights of the A2780 tumor-xenograft mice were determined twice a week during the experiment. (E-H) JI017 treatment. (I-L) The effect of Z-VAD-FMK $(50 \mu \mathrm{M})$ and JI017 treatment. A2780 and OVCAR-3 cells were pre-treated with Z-VAD-FMK for $4 \mathrm{~h}$ and were subsequently treated with JI017 $(300 \mu \mathrm{g} / \mathrm{mL}, 24 \mathrm{~h})$. Cell viability was determined using the WST-1 assay; cell cytotoxicity was monitored using the LDH assay, and caspase- 3 activity was assessed using the caspase- 3 activity assay; ${ }^{*}, p<0.05$. To identify caspase- 3 cleavage, Western blot analysis was performed. $\beta$-actin was used as a protein loading control.

\subsection{JI017 Induces ER Stress in Ovarian Cancer Cells}

Intracellular calcium $\left(\mathrm{Ca}^{2+}\right)$ release from ER frequently induces ER stress and cell death via protein folding, the activation of UPR and ER homeostasis [37]. To determine whether JI017 modulates $\mathrm{Ca}^{2+}$ release, intracellular $\mathrm{Ca}^{2+}$ release assay was performed. When A2780 and OVCAR-3 cells were treated with JI017 in a time-dependent manner, intracellular $\mathrm{Ca}^{2+}$ release increased approximately 5-6 times in comparison to the control (Figure 2A). To identify the mRNA expression of ER stress markers, including ATF4 and CHOP, in JI017treated A2780 and OVCAR-3 cells in a time-dependent manner, we performed real-time PCR. JI017 treatment increased ATF4 and CHOP expression to a greater extent than the control treatment (Figure 2B,C). To study the protein expression of ER stress markers, such as GRP78, p-PERK, PERK, p-eIF2 $\alpha$, eIF2 $\alpha$, ATF4, and CHOP, in JI017-treated A2780 and OVCAR-3 cells in a time-dependent manner, we performed Western blot analyses. JI017 treatment enhanced the expression levels of GRP78, p-PERK, p-eIF2 $\alpha$, ATF4, and CHOP to a greater extent than the control treatment (Figure 2D). Many reports suggested that GRP78 regulates cell survival and cell death via cell-to-cell communication in exosome isolates [38]. To identify whether JI017 treatment induces exosomal GRP78 in A2780 and OVCAR-3 cells, we isolated the exosome from JI017-treated ovarian cancer cell culture media and performed Western blot analyses. JI017 treatment upregulated exosomal GRP78 
and the exosome marker CD63 in a time-dependent manner (Supplementary Figure S1A). To further confirm whether JI017 mediates apoptosis through ER stress, we co-treated the A2780 and OVCAR-3 cells with JI017 and thapsigargin (TG), an ER stress inducer or 4phenylbutyric acid (4-PBA), an ER stress inhibitor. TG in combination with JI017 inhibited cell viability and increased $\mathrm{LDH}$ and $\mathrm{Ca}^{2+}$ release to a greater extent in comparison with JI017 or TG alone (Figure 2E-G). TG + JI017 induced the upregulation of GRP78, p-PERK, p-eIF2 $\alpha$, ATF4, and CHOP and caspase- 3 cleavage in A2780 and OVCAR-3 cells to a greater extent in comparison with TG or JI017 alone (Figure 2H). In combination with 4-PBA, JI017 dramatically inhibited the reduction of cell viability and enhancement of LDH cytotoxicity and $\mathrm{Ca}^{2+}$ release (Supplementary Figure S1B-D). Furthermore, Western blot analyses indicated that JI017 + 4-PBA blocked the upregulation of GRP78, p-PERK, p-eIF2 $\alpha$, ATF4, and CHOP and caspase-3 cleavage to a greater extent than JI017 alone (Supplementary Figure S1E).
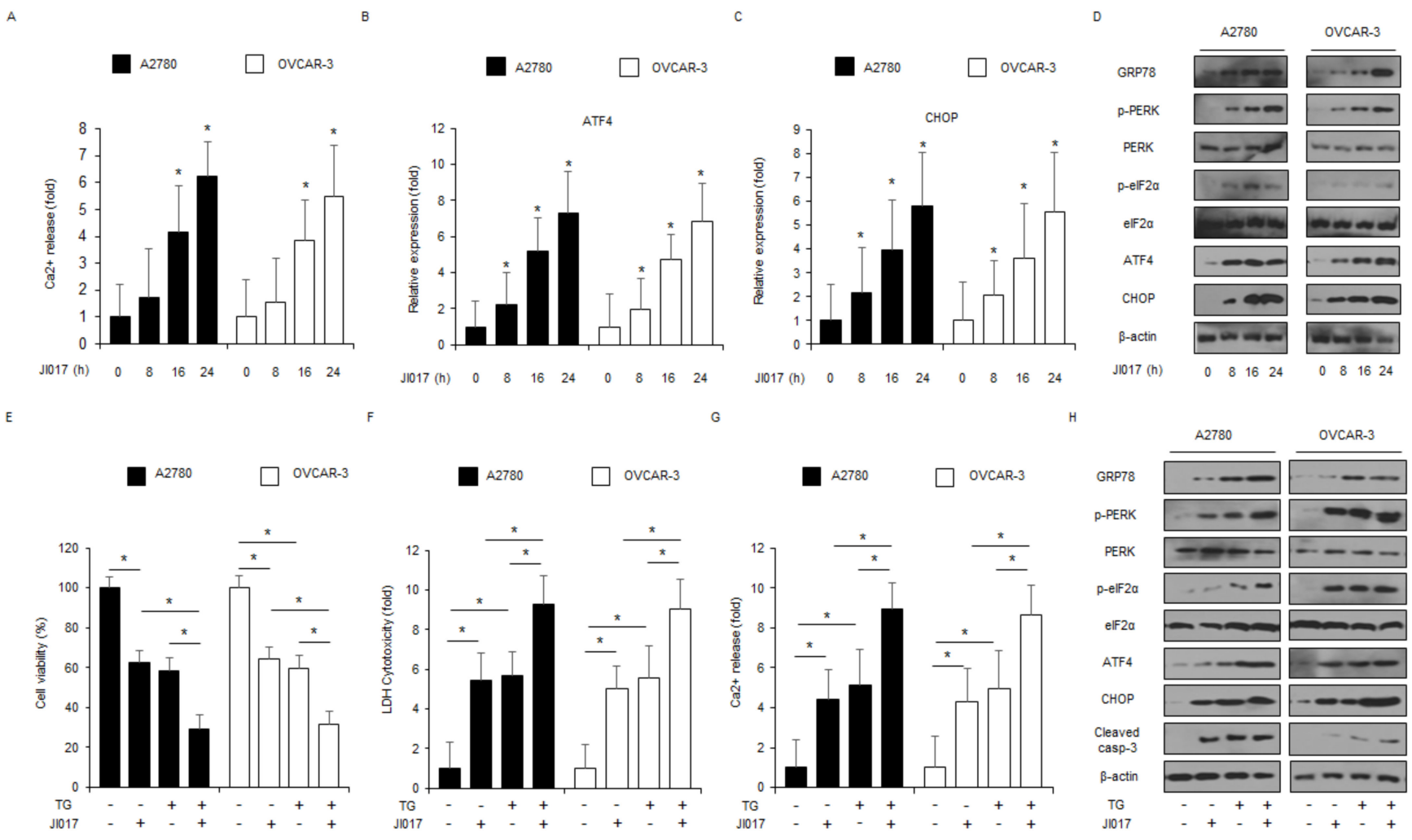

Figure 2. JI017 induces ER stress and cell death via intracellular $\mathrm{Ca}^{2+}$ release. (A) A2780 and OVCAR-3 cells were treated with JI017 $(300 \mu \mathrm{g} / \mathrm{mL})$ in a time-dependent manner $(0,8,16$, and $24 \mathrm{~h})$, and intracellular $\mathrm{Ca}^{2+}$ release was determined using intracellular $\mathrm{Ca}^{2+}$ assay. (B,C) A2780 and OVCAR-3 were treated with JI017 $(300 \mu \mathrm{g} / \mathrm{mL})$ in a time-dependent manner $(0,8,16$, and $24 \mathrm{~h})$, and mRNA levels of ATF4 and CHOP were investigated using real-time PCR. $\beta$-actin was used as a housekeeping gene. (D) A2780 and OVCAR-3 cells were treated with JI017 (300 $\mu \mathrm{g} / \mathrm{mL})$ for the indicated times $(0,8,16$, and $24 \mathrm{~h}$ ), and the activation of ER stress signaling, including GRP78, p-PERK, PERK, p-eIF2 $\alpha$, eIF2 $\alpha$, ATF4, and CHOP, was assessed using Western blot analyses. $\beta$-actin was used as a protein loading control. (E-H) Western blot analysis of GRP78, p-PERK, PERK, p-eIF2 $\alpha$, eIF2 $\alpha$, ATF4, CHOP, and cleaved caspase-3 levels were determined using WST-1 assay, $\mathrm{LDH}$ assay, and intracellular $\mathrm{Ca}^{2+}$ assay in thapsigargin (TG; $\left.3 \mu \mathrm{M}, 24 \mathrm{~h}\right)$ - and JI017 (300 $\mu \mathrm{g} / \mathrm{mL}, 24 \mathrm{~h}$ )-treated ovarian cancer cells; ${ }^{*}, p<0.05$.

\subsection{GRP78 Loss Blocks JI017-Induced ER Stress and Apoptosis in Ovarian Cancer Cells}

To validate if JI017 regulates the master regulator of ER stress GRP78, GRP78-specific siRNAs were transfected into A2780 and OVCAR-3 cells and then treated with JI017. A knockdown experiment using GRP78 siRNAs showed the inhibition of the reduction of cell viability and increase of $\mathrm{LDH}$ release, $\mathrm{Ca}^{2+}$ release, and caspase- 3 activity in comparison to 
the knockdown of control siRNA in JI017-treated A2780 and OVCAR-3 cells (Figure 3A-D). Western blot analyses revealed that GRP78 loss decreased GRP78, p-PERK, PERK, p-eIF2 $\alpha$, eIF2 $\alpha$, ATF4, and CHOP expression and caspase-3 cleavage levels in JI017-treated A2780 and OVCAR-3 cells to a greater extent (Figure 3E). Further, GRP78 knockdown downregulated the expression levels of exosomal GRP78 in JI017-treated A2780 and OVCAR3 cells (Supplementary Figure S2). These results indicate that targeting GRP78 blocks ER stress and apoptosis in JI017-treated ovarian cancer cells.

A
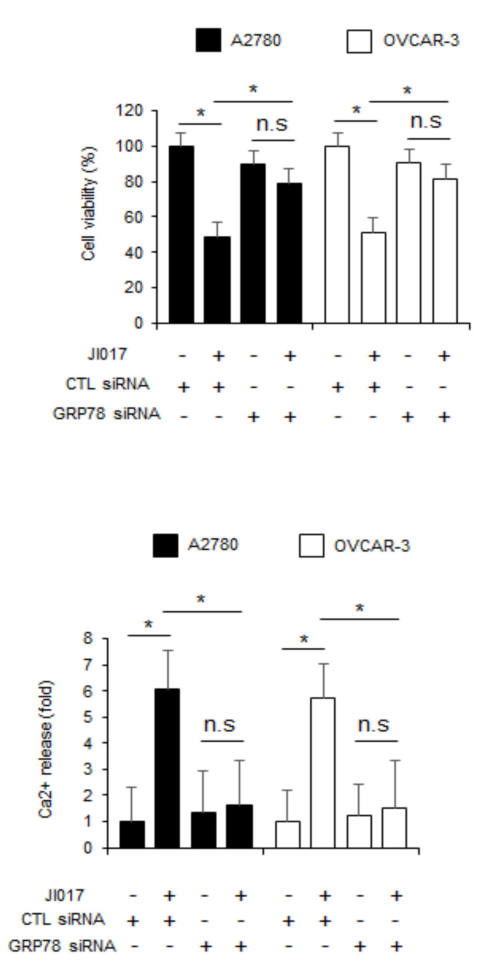
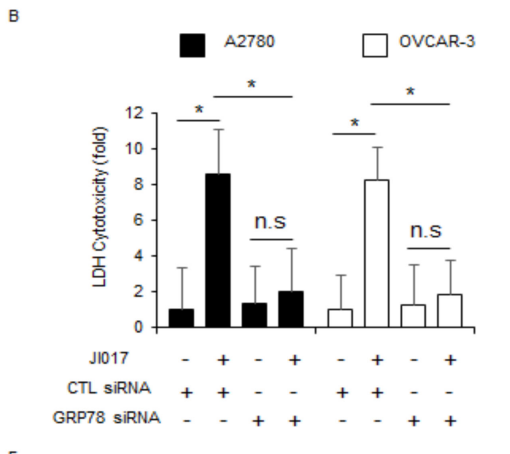

E

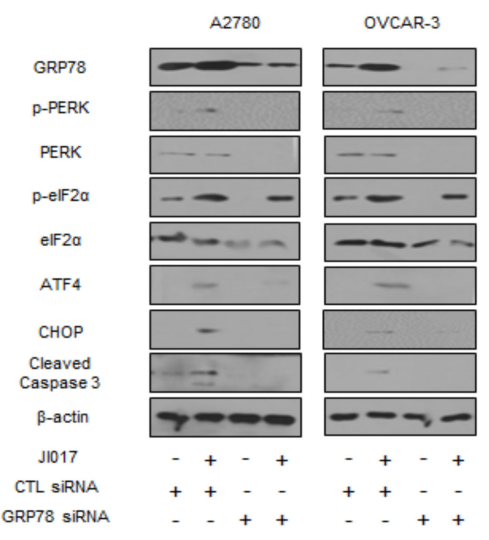

Figure 3. GRP78 inhibition suppresses JI017-induced ER stress and cell death in ovarian cancer cells. (A-D) A2780 and OVCAR-3 cells were transfected with GRP78-specific siRNA in the presence or absence of JI017 (300 $\mu \mathrm{g} / \mathrm{mL}, 24 \mathrm{~h})$, and WST-1, LDH, caspase-3 activity, and intracellular $\mathrm{Ca}^{2+}$ assay were performed; ${ }^{*}, p<0.05$. (E) Western blot analysis of GRP78, p-PERK, PERK, p-eIF2 $\alpha$, eIF2 $\alpha$, ATF4, CHOP, and cleaved caspase-3 in JI017 (300 $\mu \mathrm{g} / \mathrm{mL}, 24 \mathrm{~h}$ )-treated A2780 and OVCAR-3 cells in the presence or absence of GRP78 siRNA (30 nM, $24 \mathrm{~h})$. $\beta$-actin was used as a protein loading control.

\subsection{Targeting PERK and CHOP Suppresses Apoptosis via the Inhibition of ER Stress in J1017-Treated Ovarian Cancer Cells}

To evaluate the contribution of PERK and CHOP activation in ER stress-mediated apoptosis, PERK- and CHOP-specific siRNAs were transfected into A2780 and OVCAR-3 cells, and the cells were treated with JI017. Compared with the transfection of control siRNA in JI017-treated A2780 and OVCAR-3 cells, transfection of PERK and CHOP siRNAs in these cells inhibited the reduction of cell viability and the increase of $\mathrm{LDH}$ and $\mathrm{Ca}^{2+}$ release to a greater extent (Figure $4 \mathrm{~A}-\mathrm{C}, \mathrm{E}-\mathrm{G}$ ). Western blot analyses revealed that PERK knockdown decreased p-PERK, ATF4, and CHOP expression and caspase-3 cleavage levels in JI017-treated A2780 and OVCAR-3 cells to a greater extent (Figure 4D). In addition, CHOP knockdown decreased CHOP expression and caspase-3 cleavage levels in JI017treated A2780 and OVCAR-3 cells to a greater extent (Figure 4H). These results indicate that targeting PERK and CHOP suppresses ER stress and apoptosis by JI017 treatment in ovarian cancer cells. 


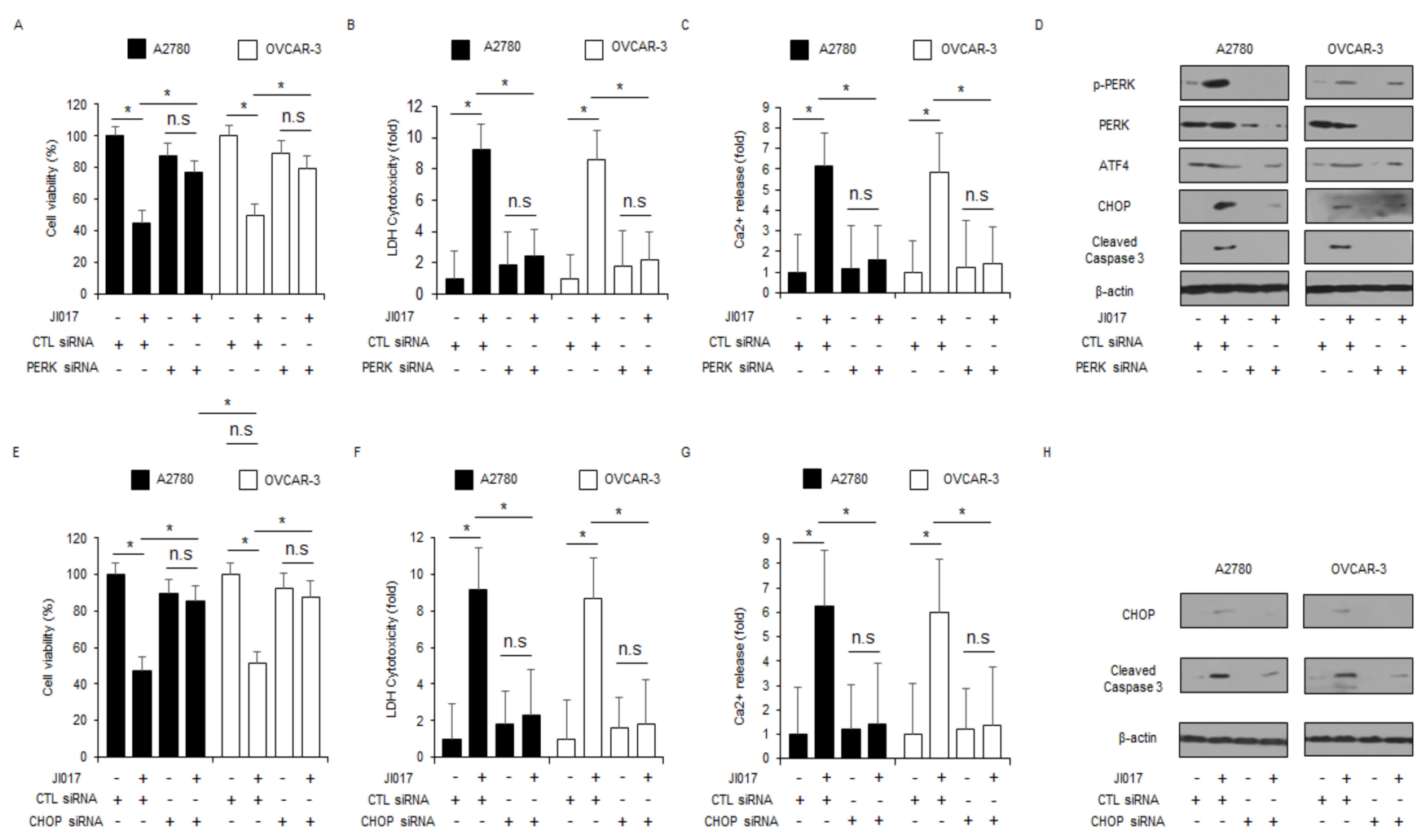

Figure 4. Targeting of ER stress signaling blocks JI017-induced cell death in ovarian cancer cells. (A-D) After A2780 and OVCAR-3 cells were transfected with PERK (30 nM, 24 h), the WST-1 assay, LDH cytotoxicity assay, intracellular Ca ${ }^{2+}$ assay, and Western blot analyses were performed with/without JI017 (300 $\mu \mathrm{g} / \mathrm{mL}, 24 \mathrm{~h})$ treatment.; ${ }^{*}, p<0.05$. Western blot analyses were performed to identify the ER stress-related genes p-PERK, PERK, ATF4, and CHOP and caspase-3 cleavage in JI017-treated PERK knockdown cells. $\beta$-actin was used as a protein loading control. (E-H) After A2780 and OVCAR-3 cells were transfected with CHOP (30 nM, 24 h), WST-1, LDH cytotoxicity assay, intracellular Ca ${ }^{2+}$ assay, and Western blot analyses were performed with/without JI017 $(300 \mu \mathrm{g} / \mathrm{mL}, 24 \mathrm{~h})$ treatment.; ${ }^{*}, p<0.05$. Western blot analyses were performed to identify the expression of CHOP and caspase- 3 cleavage in JI017-treated CHOP knockdown cells. $\beta$-actin was used as a protein loading control.

\subsection{ROS Release by JI017 Treatment Induces ER Stress and Cell Death in Ovarian Cancer Cells}

ROS production by diverse stresses results in ER stress and apoptosis in various cancer cell types, whereas the inhibition of ROS blocks ER stress and apoptosis induced by these stressors [39]. To check for ROS release in JI017-treated ovarian cancer cells, we performed intracellular ROS assay and found that JI017 exerts intracellular ROS release in a time-dependent manner (Figure 5A). To detect whether the ROS inhibitors diphenylene iodonium (DPI) and N-acetylcysteine (NAC) suppress JI017-mediated ROS production and cell death in A2780 and OVCAR-3 cells, we performed the WST-1 assay, LDH assay, caspase- 3 activity assay, intracellular $\mathrm{Ca}^{2+}$ assay, and intracellular ROS assay. Compared with JI017 treatment alone, DPI + JI017 or NAC + JI017 treatment inhibited the decrease of cell viability and increase of LDH release, caspase-3 activity, ROS release, and $\mathrm{Ca}^{2+}$ production to a greater extent (Figure 5B-F). Western blot analyses revealed that compared with JI017 treatment alone, DPI/JI017 or NAC/JI017 treatment inhibited p-PERK and $\mathrm{CHOP}$ expression to a greater extent, indicating the suppression of ER stress and cell death by JI017-induced ROS release (Figure 5G). These results suggest that J017 induces ER stress and apoptosis by releasing ROS in ovarian cancer cells. 


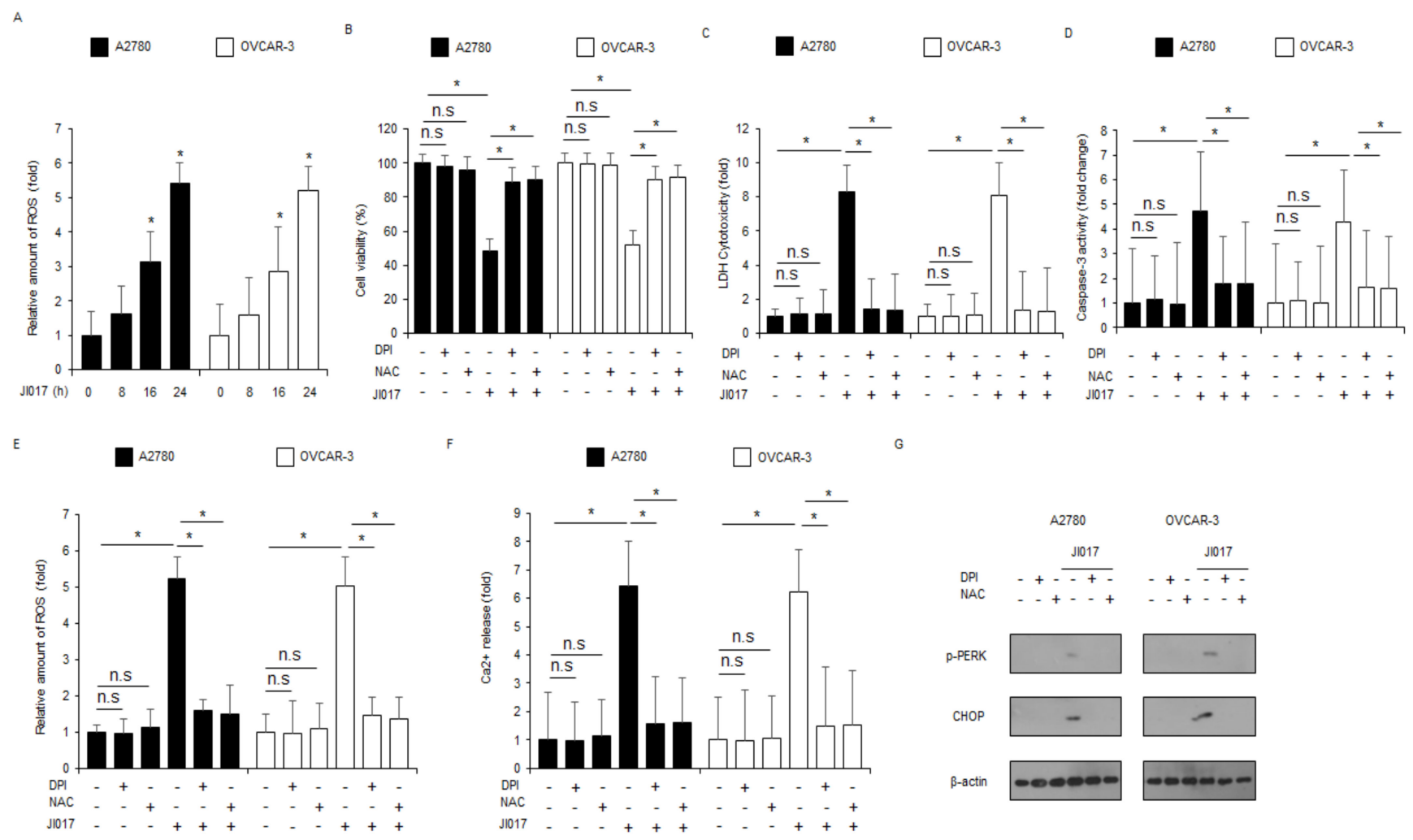

Figure 5. ROS inhibition by DPI or NAC blocks JI017-induced ER stress and cell death in ovarian cancer cells. (A) The fluorescence data indicates intracellular ROS production by DCFDA dye in JI017 (0, 8, 16, and $24 \mathrm{~h} ; 300 \mu \mathrm{g} / \mathrm{mL})$-treated A2780 and OVCAR-3 cells. (B-G) A2780 and OVCAR-3 cells were pretreated with DPI $(1 \mu \mathrm{M})$ and NAC (100 $\mu \mathrm{M})$ for $4 \mathrm{~h}$ and subsequently treated with JI017 (300 $\mu \mathrm{g} / \mathrm{mL}, 24 \mathrm{~h})$. WST-1, LDH cytotoxicity assay, caspase-3 activity assay, ROS assay, intracellular $\mathrm{Ca}^{2+}$ assay, and Western blot analyses were performed; ${ }^{*}, p<0.05$. (G) Western blot showing p-PERK and $\mathrm{CHOP}$ levels was performed. $\beta$-actin was used as the protein loading control.

\subsection{Nox4 Is Important to JI017-Induced ROS Production and Cell Death in Ovarian Cancer Cells}

Silibinin, an active compound of milk thistle, induces ER stress and apoptosis by upregulating Nox4 and ROS release in prostate cancer cells [40]. To further investigate if Nox4 regulates JI017-induced ROS release, Nox4-specific siRNAs were transfected into A2780 and OVCAR-3 cells, and then the cells were treated with JI017. Compared with the experiment involving transfection of control siRNA in J1107-treated cells, knockdown experiment in JI017-treated A2780 and OVCAR-3 cells involving the transfection of Nox4 siRNAs indicated higher cell viability and lower LDH release, caspase-3 activity, intracellular ROS release, and intracellular $\mathrm{Ca}^{2+}$ release (Figure 6A-E). Western blot analyses revealed that compared to controls, transfection experiment involving Nox4 knockdown reduced Nox4 and CHOP levels in JI017-treated A2780 and OVCAR-3 cells to a greater extent (Figure 6F). These results indicate that targeting Nox4 blocks ER stress and apoptosis via the inhibition of Nox4 and ROS production in JI017-treated ovarian cancer cells. 

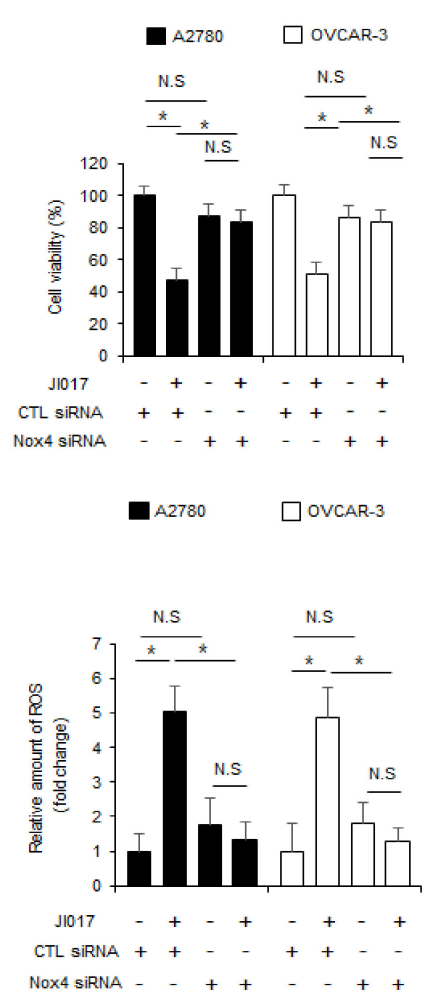

в

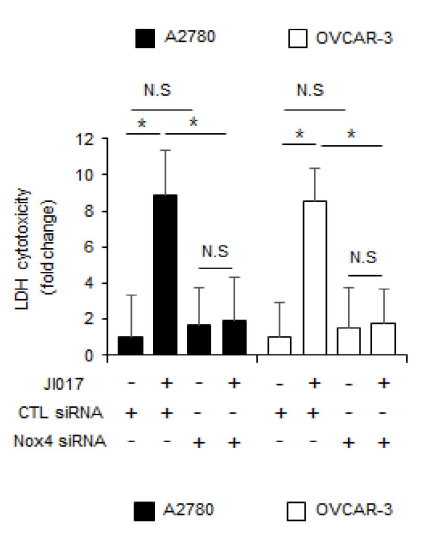

c
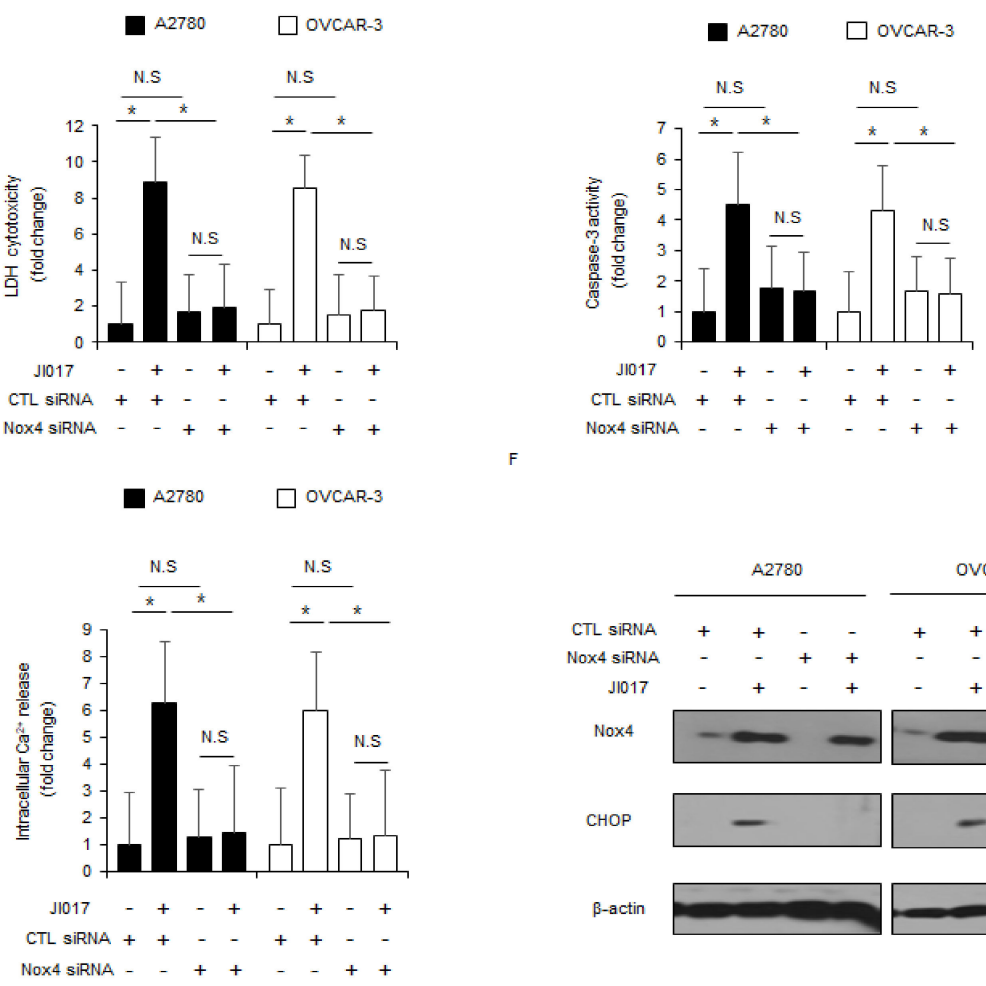

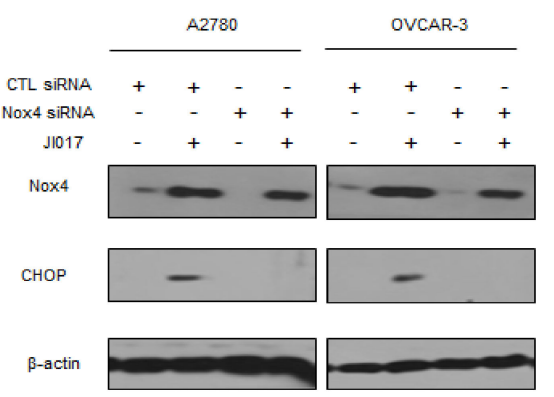

Figure 6. Suppression of Nox4 inhibits JI017-caused ER stress and cell death in ovarian cancer cells. (A-F) A2780 and OVCAR-3 cells were transfected with Nox4 siRNAs and treated with JI017 (300 $\mu \mathrm{g} / \mathrm{mL}, 24 \mathrm{~h})$. Next, WST-1 assay, LDH cytotoxicity assay, caspase-3 activity assay, intracellular ROS assay, and intracellular $\mathrm{Ca}^{2+}$ assay were performed along with Western blot analyses for Nox4 and CHOP; *, $p<0.05$. $\beta$-actin was used as the protein loading control.

\subsection{Radiation in Combination with $J 1017$ Overcame Radioresistance by Inhibiting EMT Phenomenon in Ovarian Cancer Cells}

Previous studies suggested that combination treatment of ionizing radiation + ER stress inducers induces apoptosis and overcomes radioresistance in cancer cells [41,42]. To identify if combination treatment using radiation with JI017 overcomes radioresistance in ovarian cancer cells, radio-resistant A2780R and OVCAR-3R cells were studied by exposing them to radiation and performing the colony formation assay, WST-1 assay, LDH assay, Western blot analysis, and real-time PCR. The results suggested that JI017 causes a decline in surviving fraction levels depending on the dose of radiation exposure $(2,4$, and 6 Gy) in A2780, A2780R, OVCAR-3, and OVCAR-3R cells when compared with CTL cells (Figure 7A). JI017 diminished the cell viability and enhanced the LDH cytotoxicity in A2780 and OVCAR-3 cells to a greater extent than in A2780R and OVCAR-3R cells, and JI017/2 Gy induced lower cell viability and higher LDH cell cytotoxicity in A2780 and OVCAR-3 cells than in A2780R and OVCAR-3R cells; however, 2-Gy radiation alone showed no effect (Figure 7B,C). To probe if JI017/2 Gy suppresses EMT phenomenon in radioresistant ovarian cancer cells, we performed Western blot analyses and real-time PCR. In Western blotting analyses, no change in the expression levels of EMT markers was observed in A2780 and OVCAR-3 cells; treated with JI017 alone, 2 Gy alone, and 2 Gy/JI017 (Figure 7D). However, E-cadherin decreased, and N-cadherin, vimentin, Snail, and Slug increased in A2780R and OVCAR-3R cells (Figure 7D). Further, 2 Gy or JI017 alone resulted in almost no expression change, whereas JI017/2 Gy induced the upregulation of E-cadherin and downregulation of N-cadherin, vimentin, Snail, and Slug compared to the control (Figure 7D). Specifically, JI017/2 Gy had a powerful inhibitory effect on the EMT phenomenon to a greater extent than JI017 alone in A2780R and OVCAR-3R cells (Figure 7D). Furthermore, in real-time PCR analyses, no change in the expression levels of 
EMT markers was observed in A2780 and OVCAR-3 cells; treated with JI017 alone, 2 Gy alone, and 2 Gy/JI017 (Figure 7E). However, E-cadherin decreased. and N-cadherin and vimentin increased in A2780R and OVCAR-3R cells (Figure 7E). Further, 2 Gy or JI017 alone resulted in almost no expression change, whereas JI017/2 Gy induced the upregulation of E-cadherin and downregulation of N-cadherin and vimentin, compared to the control (Figure 7E). Therefore, our results indicate that JI017/2 Gy overcomes radioresistance via the inhibition of EMT phenomenon in radioresistant ovarian cancer cells.

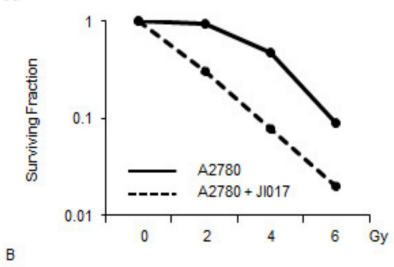

A2780 $\square$ A2780R $\square$ OVCAR-3 $\square$ OVCAR-3R
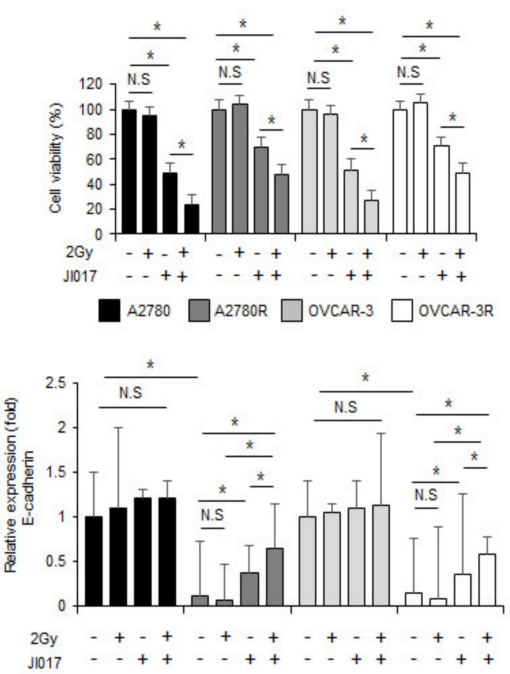
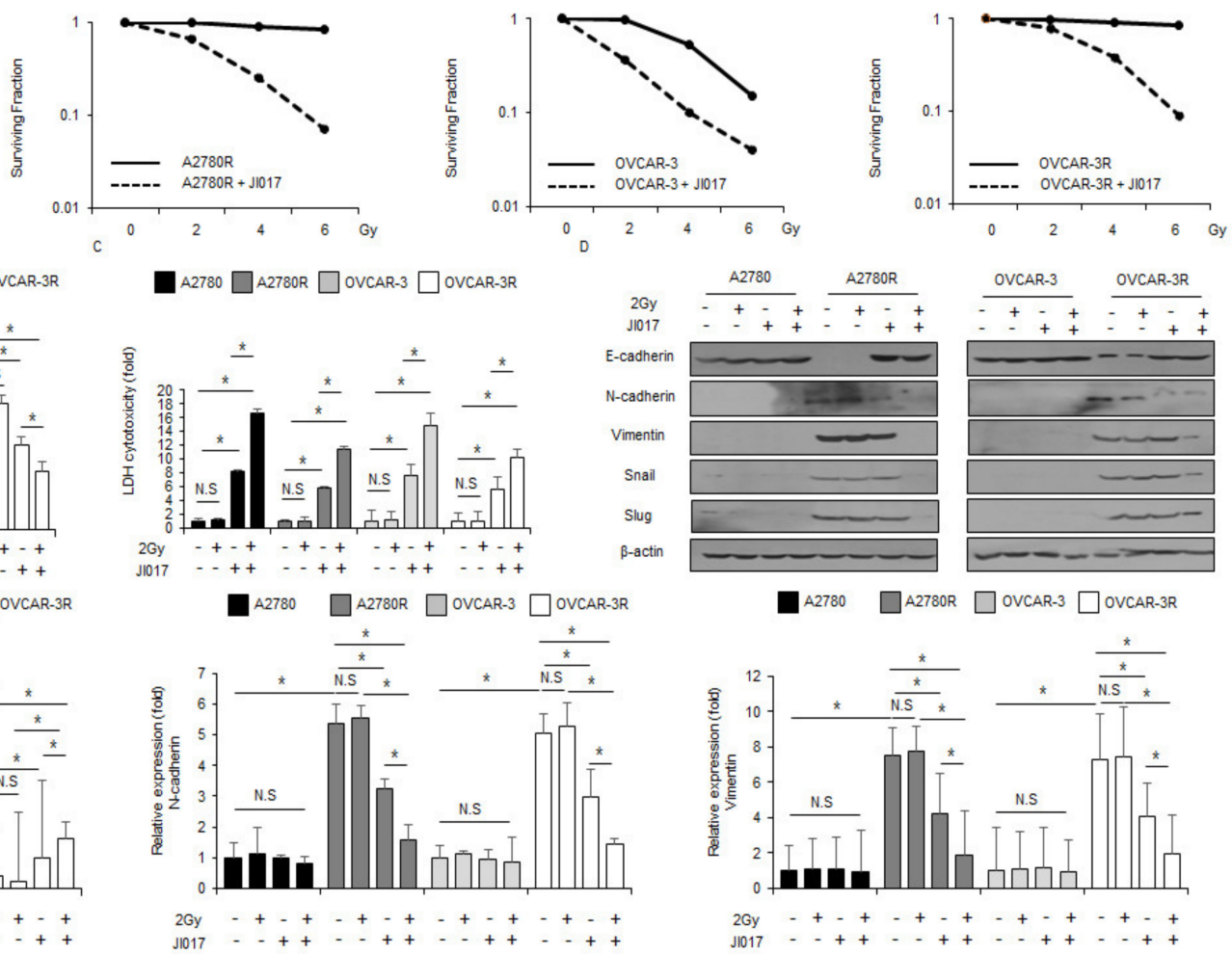

A2780 $\square$ A2780R $\square$ OVCAR-3 $\square$ OVCAR-3R

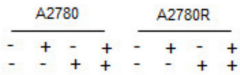
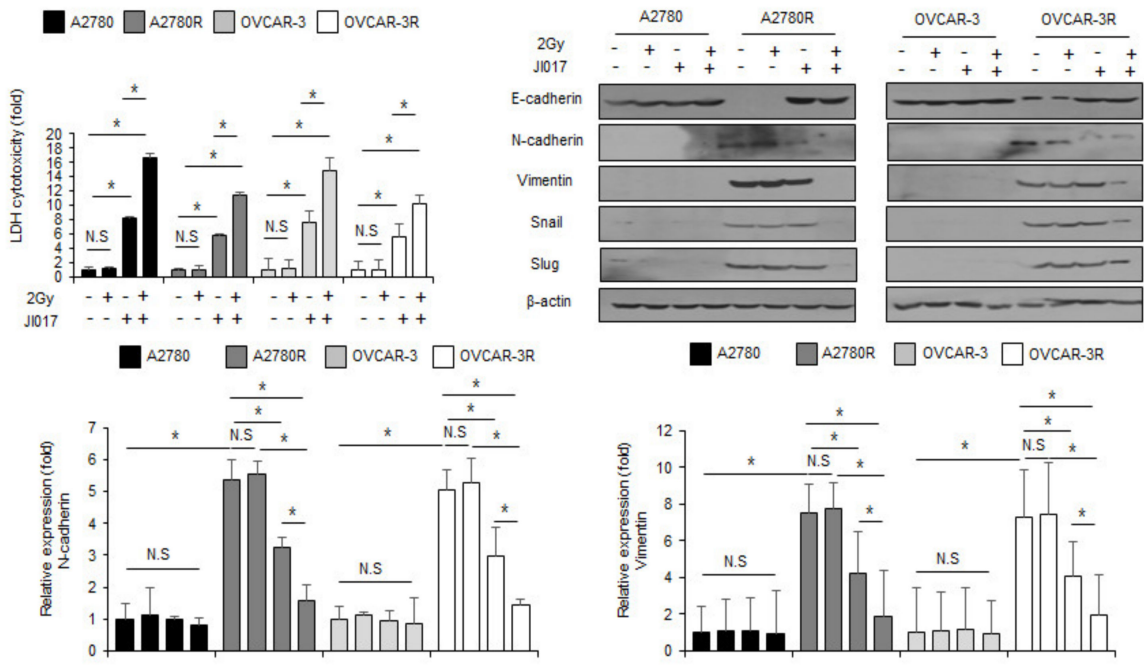

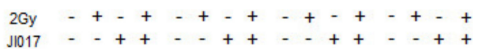

Figure 7. Combination of radiation and JI017 overcame radioresistance in radioresistant ovarian cancer cells exposed to radiation. (A) A clonogenic cell survival assay was performed at indicated doses (2, 4, or $6 \mathrm{~Gy})$ of radiation, and the survival fraction was calculated using the surviving fraction formula in A2780, A2780R, OVCAR-3, and OVCAR-3R cells; ${ }^{*}, p<0.05$. (B-E) A2780, A2780R, OVCAR-3, and OVCAR-3R cells were treated with JI017 (300 $\mu \mathrm{g} / \mathrm{mL}, 24 \mathrm{~h})$ after exposure to 2 Gy radiation. WST-1 assay and LDH assay were performed along with Western blot analyses for E-cadherin, N-cadherin, vimentin, Slug, and Snail and real-time PCR for E-cadherin, N-cadherin, and vimentin; ${ }^{*}, p<0.05$. $\beta$-actin was used as the RNA and protein loading control.

\section{Discussion}

Many researchers have developed and studied anti-cancer therapies, including chemotherapy, radiotherapy, combination therapy, laser therapy, and surgery; however, we still face serious obstacles, such as adverse effects, drug resistance, and other challenges, while developing new technology and strategies for cancer therapy [43]. Recently, plantderived herbal medicines have been explored with a focus on using alternative therapeutic strategy for effective anti-cancer treatment [44]. Many plants have been used for the therapy of various diseases, such as cancer, for a long time, and many researchers have investigated and identified herbal medicines having effective anti-cancer properties and milder adverse effects and toxicity than chemotherapy $[45,46]$. Accumulating reports suggest that herbal medicines exert potential anti-cancer effects such as apoptosis and cell cycle arrest, in various tumor types [47].

In the present study, we investigated the anti-ovarian cancer effects of novel complex herbal medication JI017 in vitro and in vivo. We demonstrated that JI017 induces apoptosis 
via the increase of Nox4, ROS release, caspase-3 activity, LDH cytotoxicity, $\mathrm{Ca}^{2+}$ release, and the decrease of cell viability in the ovarian cancer cell lines, A2780 and OVCAR-3. Furthermore, JI017 mediates ER stress and cell death by activating the PERK-eIF2 $\alpha-A T F 4-$ CHOP signaling pathway in ovarian cancer cells, and combined treatment of radiation and JI017 overcomes radioresistance by inhibiting EMT phenomena, such as the reduction of E-cadherin and the increase of $\mathrm{N}$-cadherin, vimentin, Snail, and Slug in radioresistant ovarian cancer cells.

Several reports have indicated that many herbal medicines exert anti-cancer and cytotoxicity effects by activating a severe ER stress pathway in various cancers [48]. In the emergence of unfolded protein response (UPR) by the normal ER stress, the UPR plays a protective or survival role by getting rid of misfolded or unfolded proteins; however, prolonged or excessive ER stress induces apoptosis via the activation of UPR sensors, such as PERK, IRE1 $\alpha$, and ATF6 [49]. Polyphyllin D, a potent cytotoxic saponin isolated from Paris polyphylla, induces apoptosis via the GRP78-CHOP pathway in NCI-H460 cells [30]. Dehydrocostuslactone, a sesquiterpene lactone extracted from Saussurea lappa and Aucklandia lappa, activates PERK-CHOP and IRE1 $\alpha-\mathrm{JNK}-\mathrm{CHOP}$ signaling pathways by releasing intracellular ROS and intracellular $\mathrm{Ca}^{2+}$ in NSCLC, A549, and NCI-H460 cells, leading to apoptosis [31]. Our results indicate that JI017 mediates apoptosis and excessive ER stress via intracellular ROS and $\mathrm{Ca}^{2+}$ production in A2780 and OVCAR-3 cells, and JI017 treatment contributes to caspase- 3 and caspase- 9 cleavage via the PERK-eIF2 $\alpha-$ ATF4-CHOP signaling pathway. Combination treatment of the ER stress inducer TG + JI017 induces synergistic apoptosis, ER stress, caspase-3 activity, LDH cytotoxicity, ROS production, and $\mathrm{Ca}^{2+}$ release and thereby increases the phosphorylation of PERK and eIF2 $\alpha$ and the expression of ATF4, CHOP, and caspase-3 cleavage. In contrast, targeting GRP78, PERK, and CHOP inhibits apoptosis and ER stress in JI017-treated ovarian cancer cells.

Recent reports have revealed that prolonged cellular events, such as severe ROS and $\mathrm{Ca}^{2+}$ release, have anti-cancer effects and cell death signaling via ER stress in tumor cells [50]. NADPH oxidases of the Nox family are potential components of ROS [51]. Many studies suggest that the activation of Nox4 is localized predominantly in the ER, and it excessively generates intracellular ROS and then causes apoptosis and ER stress [52]. Two isoforms of the Nox family, Nox2 and Nox4, are involved in apoptosis and ER stress via ROS release [53]. The inhibition of Nox4 by Nox4-specific siRNAs and the Nox4 inhibitor DPI block apoptosis and ER stress by preventing the expression of the ER stress proapoptotic marker CHOP, c-JNK, and apoptosis signal regulating kinase 1 (ASK1) [54]. In the present study, JI017 was found to cause ER stress-related apoptosis by activating Nox4-driven ROS formation in ovarian cancer cells A2780 and OVCAR-3 cells. In JI017-treated A2780 and OVCAR-3 cells, Nox4 inhibition blocked the reduction of cell viability and increased the release of $\mathrm{LDH}$, caspase- 3 activity, $\mathrm{ROS}$ production, $\mathrm{Ca}^{2+}$ release, as well as and ER stress responses, such as the induction of the ER stress-related proapoptotic marker CHOP. These results suggest that JI017 causes ER stress and apoptosis via the Nox4-mediated ROS production

EMT is a biological process that results in increased invasion and migration and leads to resistance, and EMT inducers, such as EMT transcription factor and EMT activator, lead to tumorigenesis and chemoresistance in various cancer types [55-57]. Many reports have suggested that clinical cancer radiotherapy frequently results in the EMT phenomenon in surviving cancer cells on ionizing radiation exposure, and radioresistance development is still a serious obstacle for radiotherapy [58]. Recent reports suggested that prolonged ER stress induced by a new drug inhibits the EMT process via the activation of UPR, and it may be a crucial tumor therapeutic strategy and pre-clinical model [59]. Marine, a herbal medicine derived from Sophora flavescens, induces anti-prostate cancer effects by activating GRP78, CHOP, and ATF4, phosphorylating eIF2 $\alpha$, and inhibiting the EMT process via the decrease of E-cadherin and the increase of $\mathrm{N}$-cadherin and vimentin [60]. Hydroxypropyl$\beta$-cyclodextrin, a cholesterol-depleting agent of lipid rafts, interferes with the EMT process via ER stress in breast cancer cell lines [61]. Nitidine chloride, a natural compound extracted 
from the root of Zanthoxylum nitidum, exerts powerful anti-glioma effect in vitro and in vivo via the inhibition of EMT markers, including N-cadherin, vimentin, and Slug, and the phosphorylation of the ER stress marker eIF2 $\alpha$ [62]. Therefore, in a radioresistant tumor environment, targeting EMT phenomena could be a potential tumor therapeutic strategy to overcome radioresistance. Our results showed that 2 Gy/JI017 overcomes radioresistance and induces cell death via the upregulation of E-cadherin and the downregulation of $\mathrm{N}$-cadherin, vimentin, Slug, and Snail.

In conclusion, the novel complex herbal medication JI017 induces apoptosis via Nox4ROS- $\mathrm{Ca}^{2+}-$ ER stress in ovarian cancer cells, and a combination therapy of radiation + JI017 overcomes radioresistance and induces apoptosis via the inhibition of EMT in radioresistant ovarian cancer cells. Our findings suggest a novel tumor therapeutic approach in tumor radiotherapy (Figure 8). However, the mechanism of anti-cancer effect in JI017-treated various cancer cell types is unclear. Further studies in future directions are needed to understand the mechanisms of JI017 in various cancer types.

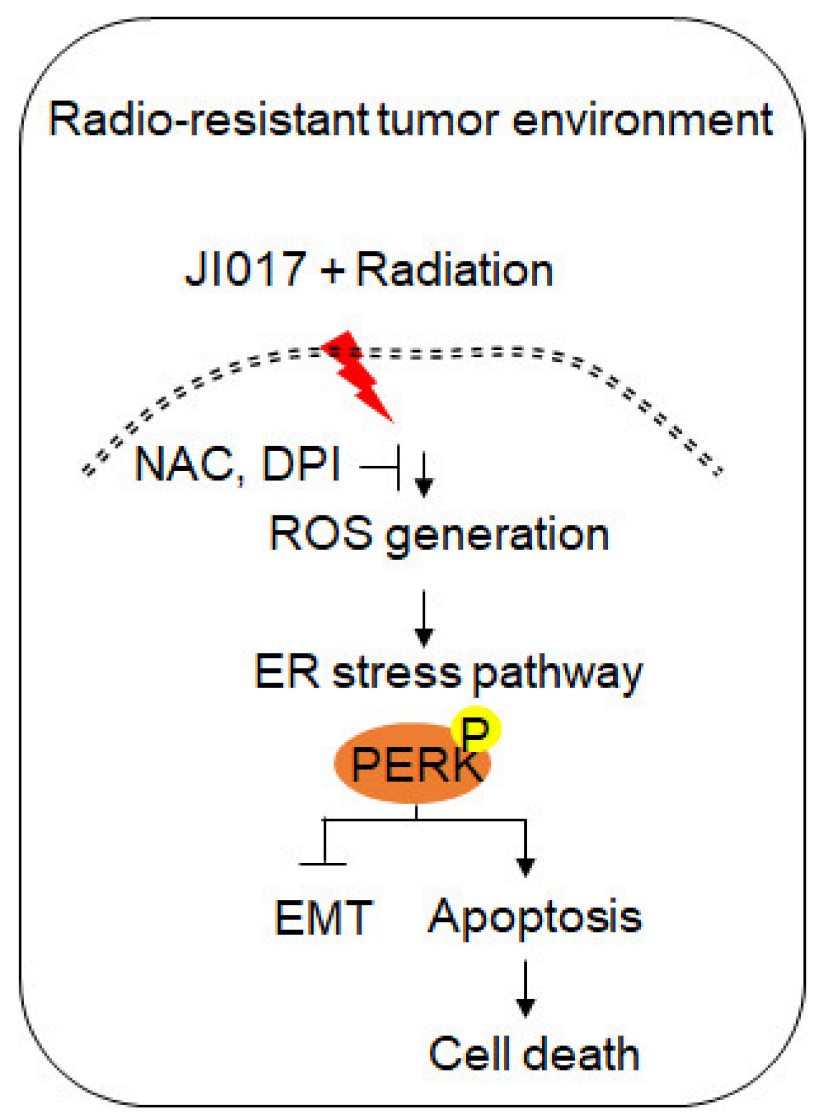

Figure 8. Schematic representation of ER stress and cell death pathways stimulated by JI017 and radiation in ovarian cancer cells and radio-resistant ovarian cancer cells.

\section{Materials and Methods}

\subsection{JI017 Extraction}

The complex herbal formula of JI017 was originally designed for cancer therapy, and the three ingredients were as follows: Astragalus gigas $(\mathrm{Ag})$, Zingiber officinale $(\mathrm{Zo})$, and processed Angelica carmichaeli (Ac). The mixtures were provided by Jaseng Hospital of Korean medicine (Seoul, Republic of Korea). The ingredients were mixed together, soaked in $70 \%$ ethanol, and extracted by treatment at $80^{\circ} \mathrm{C}$ for $3 \mathrm{~h}$, and the extract was filtered, evaporated, and lyophilized to make the JI017 powder. This was stored at $-80^{\circ} \mathrm{C}$ until use. 


\subsection{Reagents}

Compounds were obtained as follows: DPI (Nox or ROS inhibitor, Sigma Aldrich, St. Louis, MO, USA), NAC (a ROS inhibitor, Sigma Aldrich, St. Louis, MO, USA), Z-VAD-FMK (caspase inhibitor, Sigma Aldrich, St. Louis, MO, USA), 4-PBA (ER stress inhibitor, Sigma Aldrich, St. Louis, MO, USA), and TG (ER stress inducer, Millipore, Bedford, MA, USA).

\subsection{Cell Culture}

A2780 and OVCAR-3 human ovarian cancer cell lines were obtained from the American Type Culture Collection (Manassas, VA, USA). A2780 and OVCAR-3 cells were cultured in DMEM (Welgene, Daegu, South Korea) supplemented with $10 \%$ fetal bovine serum (FBS), $100 \mathrm{U} / \mathrm{mL}$ penicillin, and $100 \mathrm{mg} / \mathrm{mL}$ streptomycin (all from Welgene) and incubated at $37^{\circ} \mathrm{C}$ under a humidified $95 \% / 5 \%(\mathrm{v} / \mathrm{v})$ mixture of air and $\mathrm{CO}_{2}$. To validate the phenotypic characteristics of the ovarian cancer cell lines A2780 and OVCAR-3, we performed Western blotting analyses and identified EpCAM expression (Supplementary Figure S3).

\subsection{Cell Viability}

A2780 and OVCAR-3 human ovarian cancer cell lines were seeded into a 96-well plate with DMEM medium and grown for $24 \mathrm{~h}$. Then, cells were treated with JI017 for $24 \mathrm{~h}$. Cell viability was tested using the WST-1 assay (Roche, Indianapolis, IN, USA) according to the manufacturer's protocols. Cell absorbance was measured at $450 \mathrm{~nm}$ using an enzyme-linked immunosorbent assay reader (SpectraMax190, Microplate Reader, Molecular Devices, San Jose, CA, USA).

\subsection{LDH Assay}

A2780 and OVCAR-3 human ovarian cancer cell lines were seeded into a 96-well plate with growth medium and grown for $24 \mathrm{~h}$. Then, cells were treated with JI017 for $24 \mathrm{~h}$. LDH cytotoxicity assay was performed according to the manufacturer's protocols. The fluorescence was determined by measuring the absorbance of the samples at $490 \mathrm{~nm}$ using the ELISA reader (SpectraMax190, Microplate Reader, Molecular Devices, San Jose, CA, USA).

\subsection{Caspase-3 Activity Assay}

A2780 and OVCAR-3 human ovarian cancer cell lines were seeded into a 6-well plate with growth medium and grown for $24 \mathrm{~h}$. Caspase- 3 activity assay (the Biovision colorimetric caspase-3 assay kit) was performed according to the manufacturer's protocols. The fluorescence was measured at $405 \mathrm{~nm}$ using a spectrophotometer (Molecular Devices, San Jose, CA, USA).

\subsection{Intracellular Calcium Assays}

A2780 and OVCAR-3 human ovarian cancer cell lines were seeded into a 96-well plate with growth medium, and the cells were treated with JI017. Intracellular calcium assays were performed using a calcium assay kit (colorimetric; Abcam; ab102505) as described in the supplier's manual. The fluorescence was measured and analyzed by the absorbance of the samples at $575 \mathrm{~nm}$ using a microplate reader (Molecular Devices, San Jose, CA, USA).

\subsection{Intracellular ROS Assays}

A2780 and OVCAR-3 human ovarian cancer cell lines were seeded and incubated into a 96-well plate with growth medium. Cells were treated with JI017 and incubated with the cell permeant $2^{\prime} 7^{\prime}$-dichlorodihydrofluorescein diacetate (Invitrogen, Loughborough, UK) for $30 \mathrm{~min}$ at $37^{\circ} \mathrm{C}$ as described in the supplier's protocol. The fluorescence was measured and analyzed by the absorbance of the samples at $495 \mathrm{~nm}(\mathrm{Ex}) / 525 \mathrm{~nm}$ (Em) using a microplate reader (Molecular Devices, San Jose, CA, USA). 


\subsection{Establishment of Radioresistant A2780 and OVCAR-3 Cell Lines}

A2780 and OVCAR-3 human ovarian cancer cell lines were seeded into $60 \mathrm{~mm}$ dishes. To generate parental cell lines, these cells were exposed to a dose of 4 Gy daily for 12 weeks after $24 \mathrm{~h}$. For establishing radioresistant A2780R and OVCAR-3 cell lines, candidates for radioresistant cells were verified by comparing with parental cells.

\subsection{Irradiation}

Human ovarian cancer cells and radioresistant human ovarian cancer cells (A2780, A2780R, OVCAR-3, and OVCAR-3R) were seeded onto $60 \mathrm{~mm}$ dishes with growth medium and incubated at $37{ }^{\circ} \mathrm{C} \mathrm{CO}_{2}$ for $24 \mathrm{~h}$. Then, they were subjected to ionizing radiation exposure using ${ }^{137} \mathrm{Cs}$ source irradiation (Atomic Energy of Canada, Ltd., Mississauga, ON, Canada). After establishing radioresistant A2780R and OVCAR-3R cell lines subjected to a 4 Gy dose for 90 days, the established cells were grown in a growth medium containing $10 \%$ FBS.

\subsection{Colony Formation Assay}

Human ovarian cancer cells and radioresistant human ovarian cancer cells (A2780, A2780R, OVCAR-3, and OVCAR-3R) were seeded onto $60 \mathrm{~mm}$ dishes with growth medium and grown for $24 \mathrm{~h}$ at $37^{\circ} \mathrm{C}$ in a $\mathrm{CO}_{2}$ incubator. Cells were incubated for 10 days for colony formation, and then, the colonies were stained with $0.5 \%$ crystal violet (Amresco, Solon, $\mathrm{OH}, \mathrm{USA}$ ). To calculate the survival fraction, the number of colonies formed was divided by the number of seeded cells in the control plate.

\subsection{Transfection}

A2780 and OVCAR-3 human ovarian cancer cell lines were transfected with doublestranded siRNAs (30 nmol/mL), such as GRP78 (Santacruz, Dallas, TX, USA), PERK (Santacruz), CHOP (Bioneer, Oakland, CA, USA), and Nox4 (Santacruz), for 24 h using Lipofectamine 2000 reagent (Invitrogen) in a 6-well plate according to the manufacturer's protocol.

\subsection{Isolation of Total RNA and Protein}

Total RNA from human ovarian cancer cell lines A2780 and OVCAR-3 was prepared from a $100 \mathrm{~mm}$ cell culture dish using Trizol reagent according to the manufacturer's instructions (Invitrogen). Proteins from the cell lysates were collected by radioimmunoprecipitation assay lysis buffer (Bio-rad, Watford, UK). The supernatant was analyzed to quantify the proteins using the BCA method (Thermo Scientific, Waltham, MA, USA).

\subsection{Real-Time PCR and Western Blot Analyses}

Real-time PCR was performed in triplicate using an ABI Power SYBR green PCR Master Mix (Applied Biosystems, Waltham, UK) with E-cadherin-specific primers (5'GAACGCATTGCCACATACAC-3' (sense) and 5'-GAATTCGGGCTTGTTGTCAT-3' (antisense)), N-cadherin-specific primers (5'-GGCATACACCATG CCATCTT-3' (sense) and $5^{\prime}$ GTGCATGAAGGACAGCCTCT-3' (antisense)), vimentin-specific primers (5'-GAGAACTT TGCCGTTGAAGC-3' (sense) and 5'-GCTTCCTGTAGGTGGCAATC-3' (antisense)), ATF4specific primers ((5'-AAGCCTAGGTCTCTTAGATG-3' (sense) and $5^{\prime}$ - TTCCAGGTCATCT ATACCCA- $3^{\prime}$ (antisense)), and CHOP-specific primers ((5' - ATGAGGACCTGCAAGAGGT CC-3' (sense) and $5^{\prime}$-TCCTCCTCAGTCAGCCAAGC- $3^{\prime}$ (antisense)) on a Roche LightCycler 96 System (Roche). RNA quantities were normalized with $\beta$-actin primers ( $5^{\prime}$ AAGGCCAAC CGCGAGAAGAT-3' (sense) and 5'-TGATGACCTGGCCGTCAGG-3' (antisense)), and gene expression analyses were quantified according to the $2^{-\Delta \mathrm{Ct}}$ method. For the Western blot analysis, cells were solubilized in RIPA lysis buffer (Bio-rad). Then, the blocked membranes were incubated overnight at $4{ }^{\circ} \mathrm{C}$ with primary antibodies. The primary antibodies used included $\beta$-actin (Santa Cruz, 1:1000, sc-47778), eIF2 $\alpha$ (Santa Cruz, 1:1000, sc-133132), GRP78 (Santa Cruz, 1:1000, sc-166490); CD63 (Abcam, Cambridge, UK, 1:1000, ab216130); Nox4 (proteintech, 1:1000, 14347-1-AP); cleaved caspase-3 (Cell Signal- 
ing, Danvers, MA, USA, 1:1000, \#9664), cleaved caspase-9 (Cell Signaling, 1:1000, \#20750), cleaved PARP (Cell Signaling, 1:1000, \#5625), p-PERK(Thr980) (Cell Signaling, 1:1000, \#3179), PERK (Cell Signaling, 1:1000, \#5683), p-eIF2 $\alpha$ (Ser51) (Cell Signaling, 1:1000, \#3398), ATF4 (Cell Signaling, 1:1000, \#11815), CHOP (Cell Signaling, 1:1000, \#2895), E-cadherin (Cell Signaling, 1:1000, \#14472), N-cadherin (Cell Signaling, 1:1000, \#13116), Slug (Cell Signaling, 1:1000, \#9585), Snail (Cell Signaling, 1:1000, \#3879), and vimentin (Cell Signaling, $1: 1000, \# 5741)$. After washing, the membrane was incubated for $40 \mathrm{~min}$ at room temperature with a 1:4000 dilution of HRP-conjugated secondary antibodies. The secondary antibodies used included anti-mouse anti rabbit IgG HRP-linked antibody (Santa Cruz, sc-2357) and m-IgGK BP-HRP-linked antibody (Santa Cruz, sc-516102). The membranes were analyzed using ECL Prime Western Blotting Detection Reagents (Amersham, UK).

\subsection{Exosome Isolation}

A2780 and OVCAR-3 cells were treated with JI017 at the dose shown, and exosomes were obtained from the supernatant of JI017-treated A2780 and OVCAR-3 cells according to the manufacturer's protocol (Total Exosome Isolation Reagent (for cell culture media), Thermo Fisher Scientific, Waltham, MA, USA). Protein concentration was measured using the BCA method (Thermo Scientific, Waltham, MA, USA). The protein loading samples $(10 \mu \mathrm{g})$ were also quantified by Ponceau S staining and were subjected to Western blotting. Positive exosomes were identified using the exosome marker CD63.

\subsection{Animals}

For animal study, five-week-old, female, athymic BALB/c nude mice $(n u / n u)$ were purchased from OrientBio, Inc. (Daejeon, Korea) and maintained for 1 week with free access to sterile standard mouse chow (NIH-7 open formula) and water before use. Mice were housed randomly at $50 \% \pm 20 \%$ humidity and approximately $21 \pm 2{ }^{\circ} \mathrm{C}$ on a $12 \mathrm{~h}$ light-dark cycle ( $n=5$ mice/group). All animal experimental procedures were performed according to the National Institutes of Health guidelines and a protocol approved by the Institutional Animal Care and Use Committee of Kyung Hee University.

\subsection{Tumor Xenograft Mouse Models}

For the mouse xenograft experiment, six-week-old mice were inoculated with a A2780 human ovarian cancer cell line by subcutaneously (sc) implanting $1 \times 10^{7}$ cultured cells into the right thigh. Six days later, mice were grouped randomly $(\mathrm{n}=10$ per group $)$ and JI017 (400 or $600 \mathrm{mg} / \mathrm{kg}$ ) was orally administered once a day for two days. Tumor sizes on two axes ( $L$, longest axis; $W$, shortest axis) were measured three times per week using Vernier calipers. Tumor volume was calculated using the formula $\left(L \times W^{2}\right) / 2\left(\mathrm{~mm}^{3}\right)$.

\subsection{Statistical Analysis}

All results were confirmed via at least three independent experiments; Student's $t$-test was used to compare the means of quantitative data between groups, and a $p$ value $<0.05$ was considered statistically significant.

Supplementary Materials: The following are available online at https:/ /www.mdpi.com/article/10 .3390/ijms222212264/s1, Figures S1-S3.

Author Contributions: Conceived and designed the experiments: T.K., S.-G.K., performed the experiments: T.K., analyzed the data: T.K., wrote the paper: T.K., supervised the research: S.-G.K. All authors have read and agreed to the published version of the manuscript.

Funding: This work was supported by the national Research Foundation of Korea (NRF) grant funded by Korean government (MIST) (no.2020R1A5A2019413).

Institutional Review Board Statement: All procedures were carried out in accordance with the National Institutes of Health Guide for the Care and Use of Laboratory Animals and approved by the Institutional Animal Care and Use Committee (IACUC) at the Kyung Hee University. 
Informed Consent Statement: Not applicable.

Data Availability Statement: Not applicable.

Conflicts of Interest: The authors declare no biomedical financial interests or competing financial interests.

\section{References}

1. Reid, B.M.; Permuth, J.B.; Sellers, T.A. Epidemiology of ovarian cancer: A review. Cancer Biol. Med. 2017, 14, 9-32.

2. Chen, V.W.; Ruiz, B.; Killeen, J.L.; Wu, X.C.; Correa, C.N.; Howe, H.L. Pathology and classification of ovarian tumors. Cancer 2003, 97, 2631-2642. [CrossRef] [PubMed]

3. Sankaranarayanan, R.; Ferlay, J. Worldwide burden of gynaecological cancer: The size of the problem. Best Pract. Res. Clin. Obstet. Gynaecol. 2006, 20, 207-225. [CrossRef] [PubMed]

4. Chandra, A.; Pius, C.; Nabeel, M.; Nair, M.; Vishwanatha, J.; Ahmad, S.; Basha, R. Ovarian cancer: Current status and strategies for improving therapeutic outcomes. Cancer Med. 2019, 8, 7018-7031. [CrossRef] [PubMed]

5. $\quad$ Baskar, R.; Lee, K.A.; Yeo, R.; Yeoh, K.-W. Cancer and Radiation Therapy: Current Advances and Future Directions. Int. J. Med. Sci. 2012, 9, 193-199. [CrossRef] [PubMed]

6. Brozovic, A.; Duran, G.E.; Wang, Y.C.; Francisco, E.B.; Sikic, B.I. The miR-200 family differentially regulates sensitivity to paclitaxel and carboplatin in human ovarian carcinoma OVCAR-3 and MES-OV cells. Mol. Oncol. 2015, 9, 1678-1693. [CrossRef] [PubMed]

7. Loret, N.; Denys, H.; Tummers, P.; Berx, G. The Role of Epithelial-to-Mesenchymal Plasticity in Ovarian Cancer Progression and Therapy Resistance. Cancers 2019, 11, 838. [CrossRef] [PubMed]

8. Wang, X.; Zhang, H.; Chen, X. Drug resistance and combating drug resistance in cancer. Cancer Drug Resist. 2019, 2, 141-160. [CrossRef] [PubMed]

9. Kweon, B.; Han, Y.H.; Kee, J.Y.; Mun, J.G.; Jeon, H.D.; Yoon, D.H.; Choi, B.M.; Hong, S.H. Effect of Angelica gigas Nakai ethanol extract and decursin on human pancreatic cancer cells. Molecules 2020, 25, 2028. [CrossRef] [PubMed]

10. Hamza, A.A.; Heeba, G.H.; Hamza, S.; Abdalla, A.; Amin, A. Standardized extract of ginger ameliorates liver cancer by reducing proliferation and inducing apoptosis through inhibition oxidative stress/inflammation pathway. Biomed. Pharmacother. 2021, 134, 111102. [CrossRef] [PubMed]

11. Nedungadi, D.; Binoy, A.; Vinod, V.; Vanuopadath, M.; Nair, S.S.; Nair, B.; Mishra, N. Ginger extract activates caspase independent paraptosis in cancer cells via ER stress, mitochondrial dysfunction, AIF translocation and DNA damage. Nutr. Cancer 2021, 73, 147-159. [CrossRef]

12. Nemoto, Y.; Satoh, K.; Toriizuka, K.; Hirai, Y.; Tobe, T.; Sakagami, H.; Nakashima, H.; Ida, Y. Cytotoxic and radical scavenging activity of blended herbal extracts. Vivo 2002, 16, 327-332.

13. Akimoto, M.; Iizuka, M.; Kanematsu, R.; Yoshida, M.; Takenaga, K. Anticancer Effect of Ginger Extract against Pancreatic Cancer Cells Mainly through Reactive Oxygen Species-Mediated Autotic Cell Death. PLoS ONE 2015, 10, e0126605. [CrossRef] [PubMed]

14. Shi, H.; Zhou, C.; Li, Y.; Wang, G.; Sun, Y. Anti-inflammatory effect of aconitines. China J. Chin. Mater. Medica 1990, 15, 174-177.

15. Sharma, R.A.; Plummer, R.; Stock, J.K.; Greenhalgh, T.A.; Ataman, O.; Kelly, S.; Clay, R.; Adams, R.A.; Baird, R.D.; Billingham, L.; et al. Clinical development of new drug-radiotherapy combinations. Nat. Rev. Clin. Oncol. 2016, 13, 627-642. [CrossRef] [PubMed]

16. Begg, A.C.; Stewart, F.A.; Vens, C. Strategies to improve radiotherapy with targeted drugs. Nat. Rev. Cancer 2011, 11, 239-253. [CrossRef] [PubMed]

17. Lamouille, S.; Xu, J.; Derynck, R. Molecular mechanisms of epithelial-mesenchymal transition. Nat. Rev. Mol. Cell Biol. 2014, 15, 178-196. [CrossRef] [PubMed]

18. Thiery, J.P.; Acloque, H.; Huang, R.Y.-J.; Nieto, M.A. Epithelial-Mesenchymal Transitions in Development and Disease. Cell 2009, 139, 871-890. [CrossRef] [PubMed]

19. Wu, S.L.; Li, Y.J.; Liao, K.; Shi, L.; Zhang, N.; Liu, S.; Hu, Y.Y.; Li, S.L.; Wang, Y. 2-Methoxyestradiol inhibits the proliferation and migration and reduces the radioresistance of nasopharyngeal carcinoma CNE-2 stem cells via NF- $\mathrm{KB} / \mathrm{HIF}-1$ signaling pathway inactivation and EMT reversal. Oncol. Rep. 2017, 37, 793-802. [CrossRef]

20. Chang, L.; Graham, P.H.; Hao, J.; Ni, J.; Bucci, J.; Cozzi, P.J.; Kearsley, J.H.; Li, Y. Acquisition of epithelial-mesenchymal transition and cancer stem cell phenotypes is associated with activation of the PI3K/Akt/mTOR pathway in prostate cancer radioresistance. Cell Death Dis. 2013, 4, e875. [CrossRef]

21. Inoue, A.; Seidel, M.G.; Wu, W.; Kamizono, S.; Ferrando, A.A.; Bronson, R.T.; Iwasaki, H.; Akashi, K.; Morimoto, A.; Hitzler, J.K.; et al. Slug, a highly conserved zinc finger transcriptional repressor, protects hematopoietic progenitor cells from radiation-induced apoptosis in vivo. Cancer Cell 2002, 2, 279-288. [CrossRef]

22. Theys, J.; Jutten, B.; Habets, R.; Paesmans, K.; Groot, A.J.; Lambin, P.; Wouters, B.G.; Lammering, G.; Vooijs, M. E-Cadherin loss associated with EMT promotes radioresistance in human tumor cells. Radiother. Oncol. 2011, 99, 392-397. [CrossRef] [PubMed]

23. Mokhtari, R.B.; Homayouni, T.S.; Baluch, N.; Morgatskaya, E.; Kumar, S.; Das, B.; Yeger, H. Combination therapy in combating cancer. Oncotarget 2017, 8, 38022-38043. [CrossRef]

24. Cao, S.S.; Kaufman, R.J. Endoplasmic Reticulum Stress and Oxidative Stress in Cell Fate Decision and Human Disease. Antioxid. Redox Signal. 2014, 21, 396-413. [CrossRef] [PubMed] 
25. Perillo, B.; di Donato, M.; Pezone, A.; Di Zazzo, E.; Giovannelli, P.; Galasso, G.; Castoria, G.; Migliaccio, A. ROS in cancer therapy: The bright side of the moon. Exp. Mol. Med. 2020, 52, 192-203. [CrossRef] [PubMed]

26. Santos, C.X.C.; Nabeebaccus, A.A.; Shah, A.; Camargo, L.D.L.; Filho, S.V.; Lopes, L. Endoplasmic Reticulum Stress and NoxMediated Reactive Oxygen Species Signaling in the Peripheral Vasculature: Potential Role in Hypertension. Antioxid. Redox Signal. 2014, 20, 121-134. [CrossRef] [PubMed]

27. Zeeshan, H.M.A.; Lee, G.H.; Kim, H.-R.; Chae, H.-J. Endoplasmic Reticulum Stress and Associated ROS. Int. J. Mol. Sci. 2016, 17, 327. [CrossRef]

28. Wang, Y.-Y.; Lee, K.-T.; Lim, M.C.; Choi, J.-H. TRPV1 Antagonist DWP05195 Induces ER Stress-Dependent Apoptosis through the ROS-p38-CHOP Pathway in Human Ovarian Cancer Cells. Cancers 2020, 12, 1702. [CrossRef]

29. Abotaleb, M.; Samuel, S.M.; Varghese, E.; Varghese, S.; Kubatka, P.; Líšková, A.; Büsselberg, D. Flavonoids in Cancer and Apoptosis. Cancers 2018, 11, 28. [CrossRef]

30. Siu, F.-M.; Ma, D.-L.; Cheung, Y.-W.; Lok, C.-N.; Yan, K.; Yang, Z.; Yang, M.; Xu, S.; Ko, B.C.-B.; He, Q.-Y.; et al. Proteomic and transcriptomic study on the action of a cytotoxic saponin (Polyphyllin D): Induction of endoplasmic reticulum stress and mitochondria-mediated apoptotic pathways. Proteome 2008, 8, 3105-3117. [CrossRef]

31. Hung, J.-Y.; Hsu, Y.-L.; Ni, W.-C.; Tsai, Y.-M.; Yang, C.-J.; Kuo, P.-L.; Huang, M.-S. Oxidative and endoplasmic reticulum stress signaling are involved in dehydrocostuslactone-mediated apoptosis in human non-small cell lung cancer cells. Lung Cancer 2010, 68, 355-365. [CrossRef]

32. Moon, D.-O.; Park, S.-Y.; Choi, Y.H.; Ahn, J.S.; Kim, G.-Y. Guggulsterone sensitizes hepatoma cells to TRAIL-induced apoptosis through the induction of CHOP-dependent DR5: Involvement of ROS-dependent ER-stress. Biochem. Pharmacol. 2011, 82, 1641-1650. [CrossRef]

33. Munakarmi, S.; Shrestha, J.; Shin, H.-B.; Lee, G.-H.; Jeong, Y.-J. 3,3'-Diindolylmethane Suppresses the Growth of Hepatocellular Carcinoma by Regulating Its Invasion, Migration, and ER Stress-Mediated Mitochondrial Apoptosis. Cells 2021, $10,1178$. [CrossRef] [PubMed]

34. Mrowczynski, O.D.; Madhankumar, A.B.; Sundstrom, J.; Zhao, Y.; Kawasawa, Y.I.; Slagle-Webb, B.; Mau, C.; Payne, R.A.; Rizk, E.B.; Zacharia, B.; et al. Exosomes impact survival to radiation exposure in cell line models of nervous system cancer. Oncotarget 2018, 9, 36083-36101. [CrossRef] [PubMed]

35. Dai, J.; Su, Y.; Zhong, S.; Cong, L.; Liu, B.; Yang, J.; Tao, Y.; He, Z.; Chen, C.; Jiang, Y. Exosomes: Key players in cancer and potential therapeutic strategy. Signal. Transduct. Target. Ther. 2020, 5, 145. [CrossRef] [PubMed]

36. Liu, J.; Fan, L.; Yu, H.; Zhang, J.; He, Y.; Feng, D.; Wang, F.; Li, X.; Liu, Q.; Li, Y.; et al. Endoplasmic Reticulum Stress Causes Liver Cancer Cells to Release Exosomal miR-23a-3p and Up-regulate Programmed Death Ligand 1 Expression in Macrophages. Hepatology 2019, 70, 241-258. [CrossRef] [PubMed]

37. Amado, C.-S.; Philippe, P.; Claudio, H. Calcium signaling at the endoplasmic reticulum: Fine-tuning stress responses. Cell Calcium 2018, 70, 24-31.

38. Li, Z.; Zhuang, M.; Zhang, L.; Zheng, X.; Yang, P.; Li, Z. Acetylation modification regulates GRP78 secretion in colon cancer cells. Sci. Rep. 2016, 6, 30406. [CrossRef] [PubMed]

39. Seervi, M.; Rani, A.; Sharma, A.; Kumar, T.S. ROS mediated ER stress induces Bax-Bak dependent and independent apoptosis in response to Thioridazine. Biomed. Pharmacother. 2018, 106, 200-209. [CrossRef]

40. Kim, S.-H.; Kim, K.-Y.; Yu, S.-N.; Seo, Y.-K.; Chun, S.-S.; Yu, H.-S.; Ahn, S.-C. Silibinin induces mitochondrial NOX4-mediated endoplasmic reticulum stress response and its subsequent apoptosis. BMC Cancer 2016, 16, 1-10. [CrossRef]

41. Contessa, J.N.; Bhojani, M.S.; Freeze, H.; Rehemtulla, A.; Lawrence, T.S. Inhibition of N-Linked Glycosylation Disrupts Receptor Tyrosine Kinase Signaling in Tumor Cells. Cancer Res. 2008, 68, 3803-3809. [CrossRef] [PubMed]

42. Yamamori, T.; Meike, S.; Nagane, M.; Yasui, H.; Inanami, O. ER stress suppresses DNA double-strand break repair and sensitizes tumor cells to ionizing radiation by stimulating proteasomal degradation of Rad51. FEBS Lett. 2013, 587, 3348-3353. [CrossRef] [PubMed]

43. Barinaga, M. From bench top to beside. Science 1997, 278, 1036-1039. [CrossRef]

44. Greenwell, M.; Rahman, P. Medicinal Plants: Their Use in Anticancer Treatment. Int. J. Pharm. Sci. Res. 2015, 6, 4103-4112. [PubMed]

45. Sivaraj, R.; Rahman, P.; Rajiv, P.; Narendhran, S.; Venckatesh, R. Biosynthesis and characterization of Acalypha indica mediated copper oxide nanoparticles and evaluation of its antimicrobial and anticancer activity. Spectrochim. Acta Part A Mol. Biomol. Spectrosc. 2014, 129, 255-258. [CrossRef] [PubMed]

46. Cai, Y.-Z.; Sun, M.; Xing, J.; Luo, Q.; Corke, H. Structure-radical scavenging activity relationships of phenolic compounds from traditional Chinese medicinal plants. Life Sci. 2006, 78, 2872-2888. [CrossRef]

47. An, W.; Lai, H.; Zhang, Y.; Liu, M.; Lin, X.; Cao, S. Apoptotic Pathway as the Therapeutic Target for Anticancer Traditional Chinese Medicines. Front. Pharmacol. 2019, 10, 758. [CrossRef] [PubMed]

48. Limonta, P.; Moretti, R.M.; Marzagalli, M.; Fontana, F.; Raimondi, M.; Marelli, M.M. Role of Endoplasmic Reticulum Stress in the Anticancer Activity of Natural Compounds. Int. J. Mol. Sci. 2019, 20, 961. [CrossRef] [PubMed]

49. Xu, C.; Bailly-Maitre, B.; Reed, J.C. Endoplasmic reticulum stress: Cell life and death decisions. J. Clin. Investig. 2005, 115, 2656-2664. [CrossRef] [PubMed] 
50. Kostova, Z;; Wolf, D.H. For whom the bell tolls: Protein quality control of the endoplasmic reticulum and the ubiquitin-proteasome connection. EMBO J. 2003, 22, 2309-2317. [CrossRef]

51. Brandes, R.P.; Weissmann, N.; Schröder, K. Nox family NADPH oxidases: Molecular mechanisms of activation. Free Radic. Biol. Med. 2014, 76, 208-226. [CrossRef]

52. Prior, K.K.; Wittig, I.; Leisegang, M.S.; Groenendyk, J.; Weissmann, N.; Michalak, M.; Jansen-Dürr, P.; Shah, A.M.; Brandes, R.P. The endoplasmic reticulum chaperonecalnexin is a NADPH oxidase NOX4 interacting protein. J. Biol. Chem. 2016, 291, 7045-7059. [CrossRef] [PubMed]

53. Li, G.; Scull, C.; Ozcan, L.; Tabas, I. NADPH oxidase links endoplasmic reticulum stress, oxidative stress, and PKR activation to induce apoptosis. J. Cell Biol. 2010, 191, 1113-1125. [CrossRef] [PubMed]

54. Pedruzzi, E.; Guichard, C.; Ollivier, V.; Driss, F.; Fay, M.; Prunet, C.; Marie, J.-C.; Pouzet, C.; Samadi, M.; Elbim, C.; et al. NAD(P)H Oxidase Nox-4 Mediates 7-Ketocholesterol-Induced Endoplasmic Reticulum Stress and Apoptosis in Human Aortic Smooth Muscle Cells. Mol. Cell. Biol. 2004, 24, 10703-10717. [CrossRef] [PubMed]

55. Myung, J.K.; Choi, S.A.; Kim, S.-K.; Wang, K.-C.; Park, S.-H. Snail plays an oncogenic role in glioblastoma by promoting epithelial mesenchymal transition. Int. J. Clin. Exp. Pathol. 2014, 7, 1977-1987. [PubMed]

56. Han, S.; Kim, J.-H.; Han, M.-E.; Sim, H.-E.; Kim, K.-S.; Yoon, S.; Baek, S.-Y.; Kim, B.-S.; Oh, S.-O. SNAI1 is Involved in the Proliferation and Migration of Glioblastoma Cells. Cell. Mol. Neurobiol. 2011, 31, 489-496. [CrossRef]

57. Siebzehnrubl, F.A.; Silver, D.J.; Tugertimur, B.; Deleyrolle, L.P.; Siebzehnrubl, D.; Sarkisian, M.R.; Devers, K.G.; Yachnis, A.T.; Kupper, M.D.; Neal, D.; et al. The ZEB1 pathway links glioblastoma initiation, invasion and chemoresistance. EMBO Mol. Med. 2013, 5, 1196-1212. [CrossRef]

58. Zhang, H.; Luo, H.; Jiang, Z.; Yue, J.; Hou, Q.; Xie, R.; Wu, S. Fractionated irradiation-induced EMT-likephenotype conferred radioresistancein esophageal squamous cell carcinoma. J. Radiat. Res. 2016, 57, 370-380. [CrossRef]

59. Hetz, C. The unfolded protein response: Controlling cell fate decisions under ER stress and beyond. Nat. Rev. Mol. Cell Biol. 2012, 13, 89-102. [CrossRef] [PubMed]

60. Chang, J.; Hu, S.; Wang, W.; Li, Y.; Zhi, W.; Lu, S.; Shi, Q.; Wang, Y.; Yang, Y. Matrine inhibits prostate cancer via activation of the unfolded protein response/endoplasmic reticulum stress signaling and reversal of epithelial to mesenchymal transition. Mol. Med. Rep. 2018, 18, 945-957. [CrossRef] [PubMed]

61. Wu, Y.; Zhao, Y.; He, X.; He, Z.; Wang, T.; Wan, L.; Chen, L.; Yan, N. Hydroxypropyl $\beta$ cyclodextrin attenuates the epithelial to mesenchymal transition via endoplasmic reticulum stress in MDA MB 231 breast cancer cells. Mol. Med. Rep. 2020, 21, 249-257. [CrossRef] [PubMed]

62. Chen, Z.; Zhang, J.; Xue, H.; Qian, M.; Guo, X.; Gao, X.; Xu, J.; Qi, Y.; Sun, X.; Li, G. Nitidine Chloride Is a Potential Alternative Therapy for Glioma Through Inducing Endoplasmic Reticulum Stress and Alleviating Epithelial-Mesenchymal Transition. Integr. Cancer Ther. 2020, 19, 1534735419900927. [CrossRef] [PubMed] 